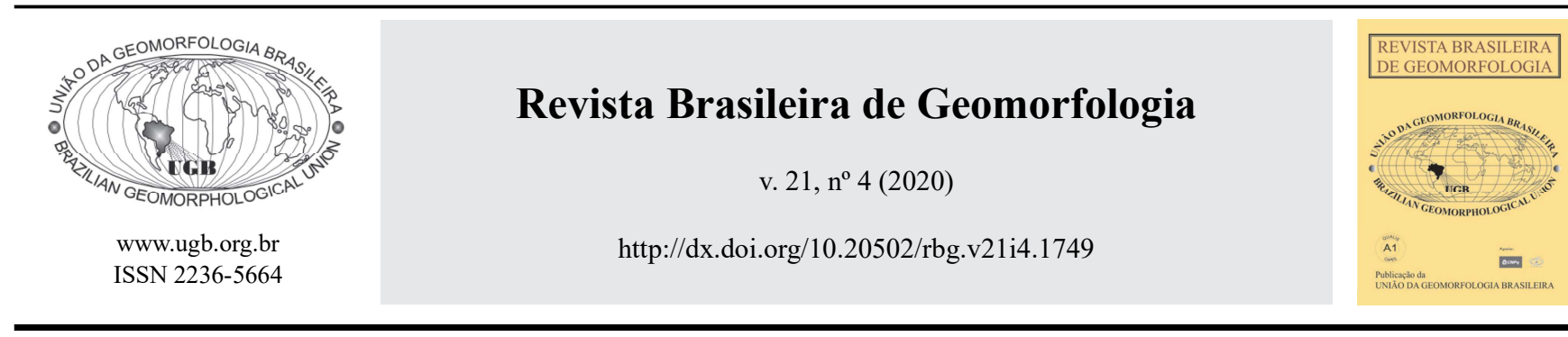

\title{
INUNDAÇÃO E EROSÃO NA COSTA NORTE DO RIO GRANDE DO SUL - BRASIL. ESTUDO DE CASO: A MARÉ METEOROLÓGICA DE OUTUBRO DE 2016
}

\author{
FLOOD AND EROSION ON THE NORTHERN COAST OF RIO GRANDE \\ DO SUL - BRAZIL. CASE STUDY: THE STORM SURGE OF OCTOBER 2016
}

\author{
Humberto Dias Vianna \\ Instituto de Oceanografia, Universidade Federal do Rio Grande \\ Av. Itália Km 8. Rio Grande, Rio Grande do Sul, Cep: 96203-900, Brasil \\ ORCID: https://orcid.org/0000-0003-2651-6382 \\ E-mail: humbertodvianna@gmail.com
}

Lauro Julio Calliari

Instituto de Oceanografia, Universidade Federal do Rio Grande Av. Itália Km 8. Rio Grande, Rio Grande do Sul, Cep: 96203-900, Brasil ORCID: https://orcid.org/0000-0002-5503-8300

E-mail:lcalliari@log.furg.br

Saionara Dias Vianna

Faculdade de Arquitetura e Urbanismo, Universidade Federal de Pelotas Rua Benjamin Constant 1359, Pelotas Cep: 96010-020, Brasil ORCID: https://orcid.org/0000-0002-1212-3337

E-mail: sdiasvianna@gmail.com

\section{Informações sobre o Artigo}

Recebido (Received):

12/08/2019

Aceito (Accepted):

23/04/2020

Palavras-chave:

Inundação; Eventos extremos; Erosão praial.

\section{Keywords:}

Flood; Extreme events, beach erosion.

\section{Resumo:}

As marés meteorológicas são comuns na costa do estado do Rio Grande do Sul e, geralmente, provocam erosão costeira. Eventos responsáveis simultaneamente por erosão e inundação expressiva são pouco frequentes. Analisa-se aqui um estudo de caso de uma maré meteorológica, que provocou erosão costeira e uma inundação incomum no litoral norte do Rio Grande do Sul. O assunto é enfocado no sentido de verificar a situação meteo-oceanográfica e os impactos associados ao fenômeno. Foram utilizados dados de ventos, ondas e nível. As fotos e vídeos do evento serviram para a identificação das altitudes inundadas, em Modelos Digitais de Superfície, e para a reconstituição da maré meteorológica no pacote Simulate Water Level Rise/Flooding, do software Global Mapper V.15. As perdas sedimentares foram estimadas para um balneário planejado e outro sem planejamento, a partir de fotos aéreas levantadas com veículo aéreo não tripulado. O evento teve duração superior a 48 horas. Os ventos atingiram, na costa, velocidades médias máximas de $42 \mathrm{~km} / \mathrm{h}$ e as rajadas chegaram a $93 \mathrm{~km} / \mathrm{h}$, ambos na direção Oeste-Sudoeste. A altura significativa das ondas atingiu 9,5 m, e a máxima $14,8 \mathrm{~m}$, na direção Sul-Sudoeste. Os volumes erodidos foram de 0,54 
$\mathrm{m}^{3} / \mathrm{m}$ no balneário planejado e $3,54 \mathrm{~m}^{3} / \mathrm{m}$ no sem planejamento, ambos distantes cerca de $22 \mathrm{~km}$. A altitude média de 2,00 $\mathrm{m}$ foi inundada, e as águas ultrapassaram os $200 \mathrm{~m}$ além das dunas frontais. A reconstrução do evento demonstrou que os balneários adjacentes às desembocaduras foram os mais impactados.

\begin{abstract}
:
Storm surges are common on the coast of the state of Rio Grande do Sul and generally cause coastal erosion. Events responsible for both erosion and significant flooding are infrequent. We analyze here a case study of a storm surge, which caused coastal erosion and an unusual flooding on the north coast of Rio Grande do Sul. The subject is focused on verifying the meteo-oceanographic situation and the impacts associated with the phenomenon. Wind, wave and level data were used. The photos and videos of the event were used to identify the flooded altitudes, in Digital Surface Models, and to reconstitute the storm surge in the Simulate Water Level Rise/Flooding package, from the Global Mapper V.15 software. Sedimentary losses were estimated for a planned and unplanned coastal towns, based on aerial photos taken with an unmanned aerial vehicle. The event lasted more than 48 hours. Winds reached, on the coast, maximum average speeds of $42 \mathrm{~km} / \mathrm{h}$ and gusts reached $93 \mathrm{~km} / \mathrm{h}$, both in the West-Southwest direction. The significant wave height reached $9.5 \mathrm{~m}$, and the maximum $14.8 \mathrm{~m}$, in the South-Southwest direction. The eroded volumes were $0.54 \mathrm{~m}^{3} / \mathrm{m}$ in the planned coastal town and $3.54 \mathrm{~m} / 3$ in the unplanned coastal town, both about $22 \mathrm{~km}$ apart. The average altitude of $2.00 \mathrm{~m}$ was flooded, and the water reached $200 \mathrm{~m}$ inland beyond the foredunes. The reconstruction of the event demonstrated that beaches adjacent to inlets were the most impacted.
\end{abstract}

\section{INTRODUÇÃO}

Marés meteorológicas ocorrem nas regiões costeiras pela ação de tempestades e ondas, que favorecem a sobre elevação do nível do mar acima da maré prevista, ocasionando inundação e erosão costeira. Consistem em oscilações do nível do mar não astronômicas (MELO FILHO, 2017). Ocorrem pela contribuição de diversos fenômenos, como o acúmulo de água junto à zona costeira pela ação de ventos fortes paralelos à costa, centro de baixa pressão, que eleva o nível do oceano, aumento da altura da arrebentação e fatores adicionais como duração do vento e presença de ciclones (MACHADO; CALLIARI; MELLO; KLEIN, 2010).

Ventos fortes são responsáveis pelo acumulo, durante horas, de grandes volumes de águas oceânicas em regiões costeiras (DARSON; ASMATH; JEHU, 2013). Ventos com grandes velocidades produzem ondas de grandes alturas e ocasionam eventos extremos na costa (HOEKE; MCINNES; O'GRADY, 2015). Os efeitos das tempestades são potencializados pelo fenômeno do barômetro inverso (PUGH, 2004).

Marés meteorológicas representam o principal risco geológico em áreas costeiras e ocasionam significativas perdas materiais, de flora, fauna e, até mesmo, humanas em todo o mundo. Elevações inferiores a 1 m no nível médio do mar afetam pântanos e a infraes- trutura costeira, e tempestades combinadas com ondas de grande altura podem dizimar toda a costa de ilhas oceânicas, como em Trinidad e Tobago (DARSON; ASMATH; JEHU, 2013).

Marés meteorológicas extremas são perigosas para as comunidades costeiras, principalmente em ilhas oceânicas já impactadas pelo turismo e aumento da população costeira, como em Samoa, no sul do Oceano Pacífico (HOEKE; MCINNES; O'GRADY, 2015). Mortes de pessoas, pela maré meteorológica, foram registradas na Baía de Eckernförde no ano de 1872 (HÖFFKEN; VAFEIDIS; MACPHERSON; DANGENDORF, 2020). Na costa noroeste da Austrália, um evento desse tipo, ocasionado por ciclone, destruiu um terço das construções na cidade de Port Hedland, o município ficou isolado por horas, nesse evento, a elevação no nível médio do mar na costa chegou a 5,7 m (HUBBERT; MCINNES, 1999).

Marés meteorológicas intensificam a capacidade erosiva das ondas, ocasionando severos danos à costa (CALLIARI; SILVA, 1998). Afetam a costa principalmente nos meses de outono e inverno, e elevações de 1,5 m no nível do oceano podem provocar inundações superiores a $3 \mathrm{~m}$ em costas com regime de micromaré (ŁABUZ, 2014). Na Baía de Eckernförde, as elevações podem chegar a $2 \mathrm{~m}$ de altura (HÖFFKEN; VAFEIDIS; MACPHERSON; DANGENDORF, 2020). 
Nas regiões estuarinas, inundações de $1 \mathrm{~m}$ podem ocasionar danos a distâncias de até $20 \mathrm{~km}$ em direção ao continente (MCGUIGAN; WEBSTER; COLLINS, 2015). Regiões estuarinas são suscetíveis a inundações provocadas por marés meteorológicas e por grandes volumes precipitados, e danos consideráveis podem ocorrer na combinação de ambos (MCGUIGAN; WEBSTER; COLLINS, 2015). Nas regiões deltaicas, como na Baía de Bengala (Bangladesh), marés meteorológicas chegam a 6 m e são potencializadas pela topografia e batimetria (LEWIS; BATES; HORSBURGH; NEAL; SCHUMANN, 2013).

A intensidade e a frequência desses eventos tornar-se-á mais frequente na escala local e global pelo aquecimento global (IPCC, 2014). Um aumento no nível médio dos mares de $5 \mathrm{~mm} /$ ano, durante os próximos 100 anos, pode intensificar os problemas devido a erosão costeira (DARSON; ASMATH; JEHU, 2013). O Painel Intergovernamental de Mudanças Climáticas estima, para o cenário AR5, um aumento máximo de $0,82 \mathrm{~m}$ no nível médio dos oceanos, esse valor inclui os efeitos devido ao derretimento das camadas de gelo nos polos da Terra (IPCC, 2014).

Na costa do Atlântico, as marés meteorológicas ocorrem quando sistemas de baixa pressão causam ventos fortes e chuvas intensas (MCGUIGAN; WEBSTER; COLLINS, 2015).No Atlântico Sul, as marés meteorológicas formam-se quando sistemas frontais, vindos do sul (centros de baixa pressão), formam ciclones extratropicais sobre o mar (SARAIVA; BEDRAN; CARNEIRO, 2003). Durante tempestades, a altura das ondas na costa pode exceder 2,5 m (GUIMARÃES; FARINA; TOLDO JUNIOR, 2014). Em águas profundas, ondas maiores que 7,5 m podem ser geradas por ciclones e provocam elevações na costa superior a 1,5 m (HOEKE; MCINNES; O'GRADY, 2015).

Marés meteorológicas, com período de retorno maior que cinco anos, estão associadas à passagem de ciclones (HOEKE; MCINNES; O'GRADY, 2015). Esses eventos estão fortemente relacionados com ciclones extratropicais de alta intensidade, que geram empilhamento de água na costa e podem alterar o perfil de praia do máximo acrescivo para o completamente erosivo no período de poucos dias e, até mesmo, horas (MACHADO; CALLIARI; MELLO; KLEIN, 2010). As marés meteorológicas atingem centenas de quilômetros, e há correlação entre locais que sofrem erosão e a trajetória de tempestades extratropicais (MACHADO; CALLIARI, 2016).

As marés meteorológicas ocasionam erosão nas dunas frontais e o colapso em edificações próximas à linha d'água. Os impactos são potencializados com a remoção das dunas frontais, proteção natural dos sistemas costeiros, e por sangradouros, que possibilitam a entrada das águas além do perfil ativo da praia (DUTRA, 2008). Processos erosivos em dunas frontais ocasionados por marés meteorológicas foram mensurados no norte da França, no balneário Vougot (SUANEZ; CANCOUËT; FLOC'H; BLAISE; ARDHUIN; FILIPOT; CARIOLET; DELACOURT, 2015). Além dos danos ecológicos, as marés meteorológicas afetam o desenvolvimento econômico em balneários com vocação turística (DARSON; ASMATH; JEHU, 2013). A ação erosiva das marés meteorológicas é potencializada pelo pico da preamar de sizígia.

As áreas utilizadas para a agricultura podem ser afetadas em elevações superiores a $5 \mathrm{~m}$ pela inundação de água salobra, arrasto das plantas e salinização do solo, principalmente em fazendas de arroz que se utilizam das áreas de baixa altitude para o plantio (DARSON; ASMATH; JEHU, 2013).

A produção de mapas contendo as áreas suscetíveis às marés meteorológicas, utilizando-se de ferramentas de geoprocessamento como laser scanning-LIDAR, é objeto de estudo em diversas partes do mundo, como na Nova Escócia-Canadá. As regiões mapeadas podem ser transformadas em camadas de informação para o uso futuro dos gestores (MCGUIGAN; WEBSTER; COLLINS, 2015).

Este trabalho teve por objetivo avaliar as causas e os impactos da maré meteorológica ocorrida em 28 de outubro de 2016, assim como identificar as áreas suscetíveis a danos promovidos por esses eventos no litoral norte do Rio Grande do Sul (RS) - Brasil.

\section{ÁREA DE ESTUDO}

A área de estudo (FIGURA 1) situa-se na planície costeira do RS e os balneários estudados ficam na Barreira IV. Essa barreira foi desenvolvida no Quaternário e possui espessura máxima de sedimentos de $1515 \mathrm{~m}$. Os balneários da região são formados por praias arenosas em quase sua totalidade, porém em Torres afloram arenitos eólicos provenientes da Formação Botucatu e rochas vulcânicas da Formação Serra Geral, ambas do Mesozoico (TOMAZELLI; VILLWOCK, 2000). 


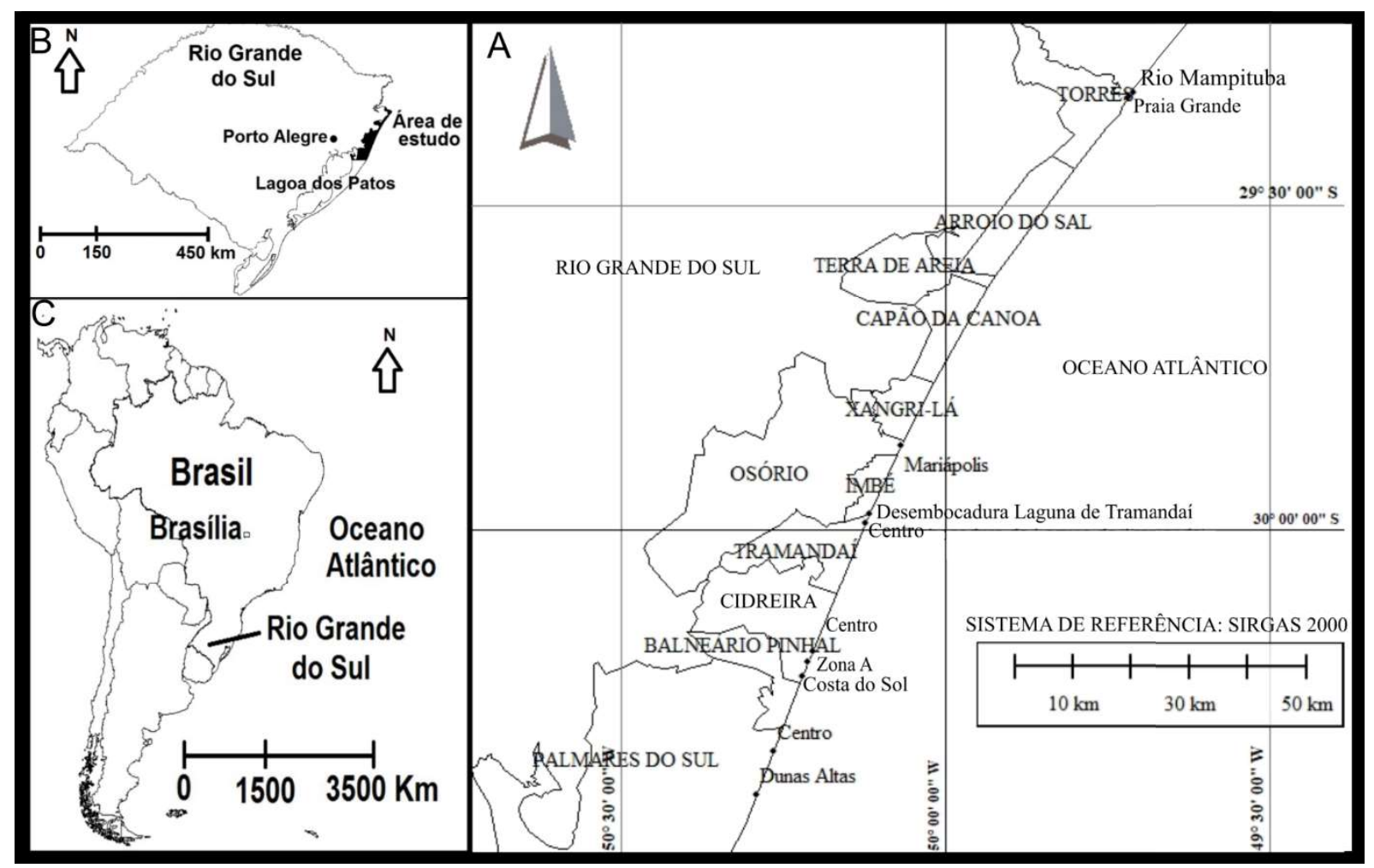

Figura 1 - Mapa de localização. A) área de Estudo; B) área de estudo no RS; C) RS na América do Sul.

A barreira IV teve sua formação a 5 ka quando o nível do mar oscilou entre 2 e $5 \mathrm{~m}$ acima do atual, dando início a formação de uma barreira constituída por sedimentos eólicos e praiais (ANGULO; LESSA; SOUZA, 2006). A barreira instalou-se no máximo transgressivo devido à grande disponibilidade de sedimentos arenosos existentes na plataforma continental interna, progradando lateralmente pelo desenvolvimento de cordões litorâneos na fase regressiva posterior (TOMAZELLI; VILLWOCK, 2000).

A plataforma continental possui entre 150 a 200 $\mathrm{km}$ de extensão, profundidades de 100 a $140 \mathrm{~m}$ e declividade suave, 0,5 a $1,5 \mathrm{~m} / \mathrm{km}$. A antepraia é constituída por depósitos arenosos, com limites externos nas profundidades de 10 e 15 m (ALMEIDA; LIMA, TOLDO Jr., 2006). Os sedimentos praiais são constituídos por areias finas unimodais e bem classificadas, com tamanho médio de 2,42 $\phi$ (VIANNA; CALLIARI, 2017).

Os balneários da área de estudo são caracterizados por praias de características intermediárias, de acordo com a classificação de Wright e Short (1984), (PEREIRA; CALLIARI; BARLETTA, 2010). O cordão de dunas é constituído por areias finas quartzosas (MARTINS, 1967), interrompido por sangradouros em diversos pontos. A altura das dunas frontais aumenta de norte a sul (CALLIARI; PEREIRA; DE OLIVEIRA;
FIGUEIREDO, 2005). As dunas de maior altura média ocorrem no balneário Dunas Altas (Palmares do Sul), e atingem 7,7 $\mathrm{m}$ de altura (VIANNA; CALLIARI, 2015). $O$ percentual de cobertura vegetal das dunas frontais varia de $85 \%$ em Palmares do Sul a $40 \%$ em Arroio do Sal, e correspondem aos estágios morfológicos, descritos por Hesp (1988), 2 (Palmares do Sul) ao 4 (Arroio do Sal), (VIANNA; CALLIARI, 2019).

Os regimes ondulatórios correspondem às vagas e ondulações, sendo a maior concentração de vagas observadas entre as direções leste (E) e leste-sudeste (ESE) no verão, com predominância de E em Tramandaí (STRAUCH; CUCHIARA; TOLDO Jr; ALMEIDA, 2009). A altura significativa de ondas no verão em Tramandaí distribui-se entre as direções leste-nordeste (ENE) e sul (S) com valores entre 1,5 a $3 \mathrm{~m}$. No outono, as alturas significativas chegam a $4,0 \mathrm{~m}$ com predominância da direção sul-sudeste (SSE). Os períodos de picos dividem-se entre as direções ENE e S, com valores de $15 \mathrm{~s}$ na direção sudeste (SE). No outono, os períodos de pico distribuem-se entre as mesmas direções observadas no verão, com períodos de $19 \mathrm{~s}$ na direção SSE.

A maré astronômica é semidiurna, com valores médios de $0,31 \mathrm{~m}$ e amplitude máxima de $0,53 \mathrm{~m}$ na primavera (ANDRADE; TOLDO; NUNES, 2018). A 
passagem de ciclones extratropicais associados a ventos e a maré astronômica na primavera pode ocasionar uma elevação no nível médio do mar superior a 3,0 m, ocasionando danos em propriedades e erosão costeira (BARLETTA; CALLIARI, 2001; ANDRADE; TOLDO; NUNES, 2018; OLIVEIRA, 2008).

$\mathrm{Na}$ costa do RS as marés meteorológicas ocorrem pela ação de ventos de orientação sudeste-sudoeste (SE-SW). Eventos desse tipo são frequentes na primavera e outono, ocasionando empilhamento de água na costa (PARISE; CALLIARI; KRUSCHE, 2009). Existe um padrão de propagação das marés meteorológicas de sul (S) para norte $(\mathrm{N})$ na costa sul-americana, os eventos que ocorrem na costa do RS estão correlacionados aos da costa sul Argentina, a velocidade de propagação das marés meteorológicas é próxima a $927 \mathrm{~km} / \mathrm{dia}$ (MELO FILHO, 2017). Elevações superiores a $1,5 \mathrm{~m}$ já foram observadas na costa do RS (CALLIARI; TOZZI; KLEIN, 1988).

Na maré meteorológica de 04 de setembro de 2006, a altura máxima das ondas na costa chegou a três metros em Tramandaí. O evento teve duração de 63 horas, provocou erosão nas dunas, estreitamento do perfil praial e danos estruturais em edificações, como o colapso do muro de contenção e calçadão de Imbé (OLIVEIRA, 2008).

Na região ocorrem, em média, de 6 a 10 sangradouros a cada $10 \mathrm{~km}$ até a desembocadura da laguna de Tramandaí, onde a média cai para 4, aumentando entre 10 a 14 em Torres. A diminuição em Tramandaí é atribuída à laguna, que dirige a drenagem superficial para o seu interior (FIGUEIREDO; CALLIARI, 2005).

O clima na área de estudo é caracterizado por ser pouco úmido, com inverno frio e verão quente. A região sofre influência dos sistemas polares, com maior participação de sistemas tropicais continentais, em associação com o efeito da continentalidade e do relevo. Os sistemas frontais são responsáveis pela maior parte das precipitações. Chove entre 1400 - $1700 \mathrm{~mm}$ ao ano de forma concentrada em 70 a 90 dias de chuva. A temperatura média anual é amena, varia de 20 a $23^{\circ} \mathrm{C}$ (ROSSATO, 2011).

TOMAZELLI (1993) efetuou a análise de séries temporais de vento, entre 1970 e 1982, obtidas das estações meteorológicas de Torres e Imbé, e determinou a direção e velocidade dominante. $\mathrm{O}$ estudo mostrou que o vento nordeste (NE) é o mais frequente, sendo procedido pelo sul (S) para Torres e oeste (O) para Imbé. A frequência do vento NE durante o ano para Torres chega a $24,1 \%$, para Imbé a $41,4 \%$.
Nas dunas da região ocorrem as espécies Calysera crassifolia, Cakile maritima, Blutaparon Portulacoides, Panicum racemosum, Senecio crassiflorus, Gamochaeta american e Hydrocotyle bonariensis. Dentre as mais importantes nas dunas frontais, Blutaparon portulacoides é vegetação pioneira que habita as dunas embrionárias, a mesma constitui-se em um obstáculo e intercepta o fluxo de areia transportado pelos ventos, sendo essa espécie responsável pela formação das dunas incipientes (SEELIGER, 1998).

Panicum racemosum, espécies mais frequente nas dunas frontais ao sul da área de estudo, ocasiona maior deposição de areia, sendo chamada de construtora das dunas (SEELIGER; CORDAZZO; BARCELLOS, 2004, CALLIARI; PEREIRA; DE OLIVEIRA; FIGUEIREDO, 2005). Spartina ciliata é outra espécie importante para a diferenciação morfológica das dunas frontais na área de estudo, a mesma é frequente nas dunas frontais de Arroio do Sal e Torres, sendo responsável pela formação de dunas do tipo nebkas (VIANNA; CALLIARI, 2019).

\section{METODOLOGIA}

Os dados meteorológicos, as rajadas, a direção e as velocidades médias dos ventos, foram obtidos junto ao Instituto Nacional de Meteorologia (INMET), em duas estações meteorológicas automáticas, uma situada nos municípios de Tramandaí (Estação A834), e outra em Torres (Estação A808), ambas instaladas a menos de $300 \mathrm{~m}$ da linha de água.

Os dados oceanográficos utilizados, validados pela Marinha do Brasil, são provenientes do Programa Nacional de Boias (PNBOIA), boia Rio Grande (B127065) fundeada a, aproximadamente, $150 \mathrm{~km} \mathrm{da}$ costa, nas coordenadas aproximadas $-30,30^{\circ}$ (latitude) e $35,28^{\circ}$ (longitude).

Os horários registrados pelas estações meteorológicas e boia estavam referidos à hora mundial - Greenwich (UTC). No trabalho, os horários foram corrigidos para o fuso de Brasília e o horário de verão vigente no período foi considerado.

O nível da desembocadura da Laguna de Tramandaí, monitorado durante o evento, foi fornecido pela Secretaria de Portos e Hidrovias do RS (SPH-RS), e foi medido por um linígrafo instalado na Estação Hidrológica de Imbé. Os dados pluviométricos não foram utilizados, devido aos baixos volumes precipitados no período estudado, a exemplo de (HUBBERT; MCINNES, 1999). 
Os vídeos e fotografias dos pontos impactados no evento foram utilizados para a delimitação dos limites alagados no software Google Earth. Uma técnica semelhante para avaliar os impactos de tempestades em zonas costeiras foi descrita por DUTRA (2008). Tais limites foram transferidos para modelos digitais de superfície, produzidos por VIANNA; CALLIARI (2015), para se determinar a altitude inundada. A altitude inundada foi inserida no pacote Simulate Water Level Rise/Flooding do software Global Mapper V.15 para a reconstituição da maré meteorológica e, posteriormente a identificação das áreas suscetíveis. Os limites inundados foram inseridos no sistema de informações geográficas para mapear a extensão máxima da inundação no terreno, de acordo com a metodologia de MCGUIGAN, WEBSTER e COLLINS (2015).

O pacote Simulate Water Level Rise/Flooding permite ao usuário simular as áreas alagadas durante uma inundação. Para tal, é necessário conhecer o aumento no nível médio do mar na costa durante a tempestade, ou a altitude máxima inundada no evento. Em áreas costeiras é possível simular o aumento do nível médio do mar a partir de uma altitude inicial de referência, por exemplo a altitude $0 \mathrm{~m}$ do modelo digital de superfície. $\mathrm{O}$ software gera polígonos que correspondem às áreas atingidas pela maré meteorológica, sendo possível ver até onde a água alcança. O pacote leva em consideração qualquer característica do terreno que impeça o fluxo, como diques, edifícios, vales ou canais de drenagem na simulação (BLUE MARBLE GEOGRAPHICS, 2020).

Os modelos digitais de superficie foram produzidos com uma nuvem de pontos LIDAR, levantada em julho de 2010, com $50 \mathrm{~cm}$ de resolução espacial e $15 \mathrm{~cm}$ de altimétrica, (VIANNA; CALLIARI, 2015). Os modelos digitais de superfície estão referenciados ao sistema SIRGAS 2000 e ao marégrafo de Imbituba (IBGE). A utilização de modelos digitais para a identificação de áreas suscetíveis às inundações foi amplamente discutida por WEBSTER, FORBES, DICKIE e SHREENAN, (2004), MCGUIGAN, WEBSTER e COLLINS (2015) e HÖFFKEN, VAFEIDIS, MACPHERSON e DANGENDORF (2020). A curva de nível $0 \mathrm{~m}$ foi considerada como a posição média da linha de costa (DARSON; ASMATH; JEHU, 2013).

$\mathrm{O}$ volume de sedimentos dunares perdidos no evento foi medido em dois balneários: Zona $\mathrm{A}$, trecho com edificações sobre as dunas frontais, e Dunas Altas, trecho com as dunas frontais preservadas. As fotos aéreas, tomadas no dia 13 de janeiro de 2017 com veículo aéreo não tripulado (VANT), foram utilizadas para a demarcação da escarpa erosiva. A delimitação da base da duna frontal foi feita no modelo digital de superfície. O VANT Dji Phantom 3 professional foi empregado no aerolevantamento. As imagens produzidas possuem 4000 por 3000 pixeis, com 72 pixeis por polegada. O volume de sedimento erodido foi estimado nos modelos digitais de superfície, com o uso do software Global Mapper V.15, entre a escarpa e base da duna frontal (FIGURA2).

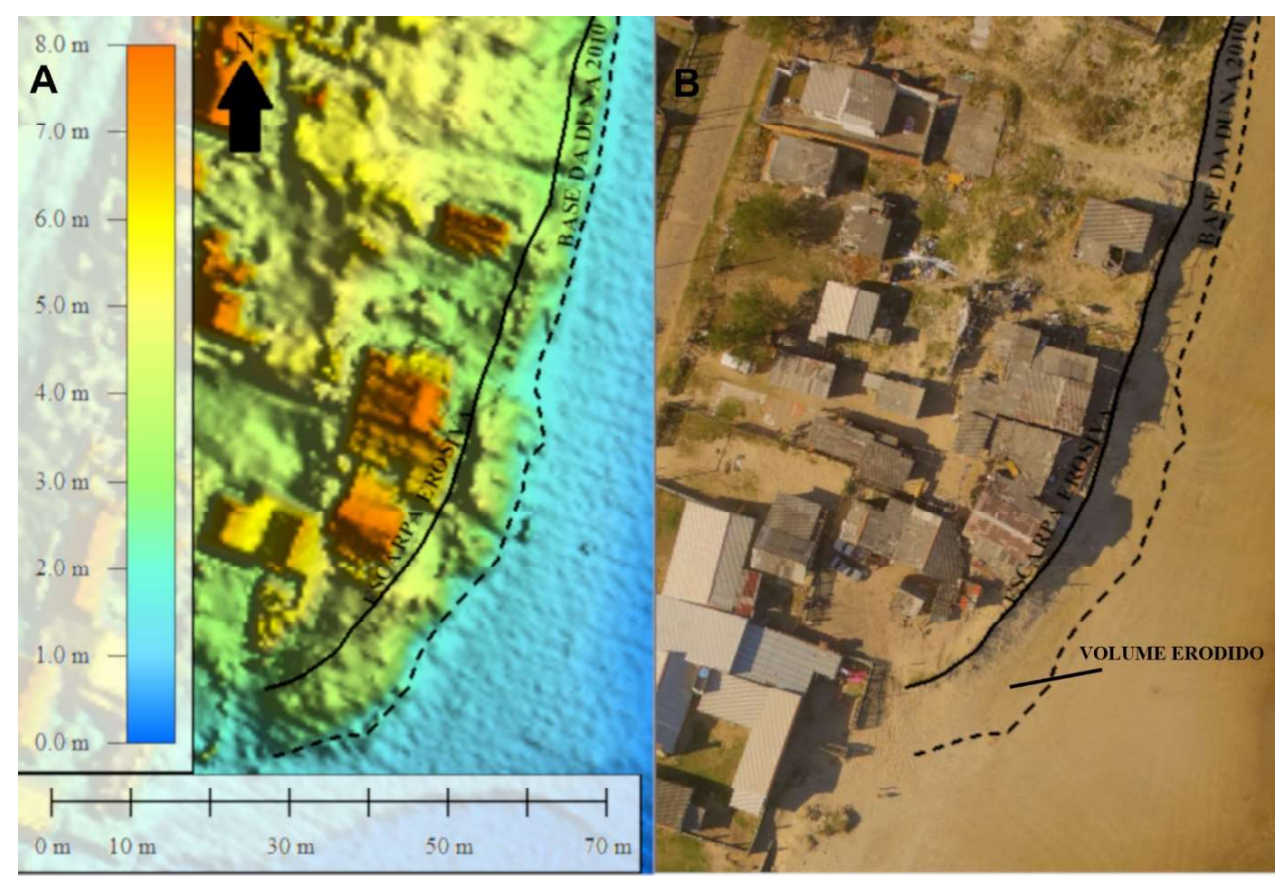

Figura 2 - Base da duna frontal (linha tracejada) e escarpa erosiva (linha contínua) demarcadas. A) no modelo digital de superficie; B) foto aérea. 


\section{RESULTADOS E DISCUSSÃO}

No dia 27/10/2016 houve a formação de um centro de baixa pressão atmosférica na costa sudeste da América do Sul, formando um vórtice na costa do RS. O evento de alta energia de onda foi, provavelmente, $o$ maior dos últimos 40 anos na costa do RS (OLIVEIRA; SIMÕES; CALLIARI; GAUTÉRIO, 2019). Sobre o
Atlântico, nas coordenadas aproximadas $38^{\circ} \mathrm{S}$ e $35^{\circ} \mathrm{W}$ (FIGURA 3), observa-se o centro do Vórtice Ciclônico de Altos Níveis, que é associado ao sistema frontal de superfície. O ciclone presente no Oceano Atlântico, relacionado à frente fria que está no Sudeste do Brasil, provocou ventos costeiros no sul e sudeste do país (CPTEC, 2016).

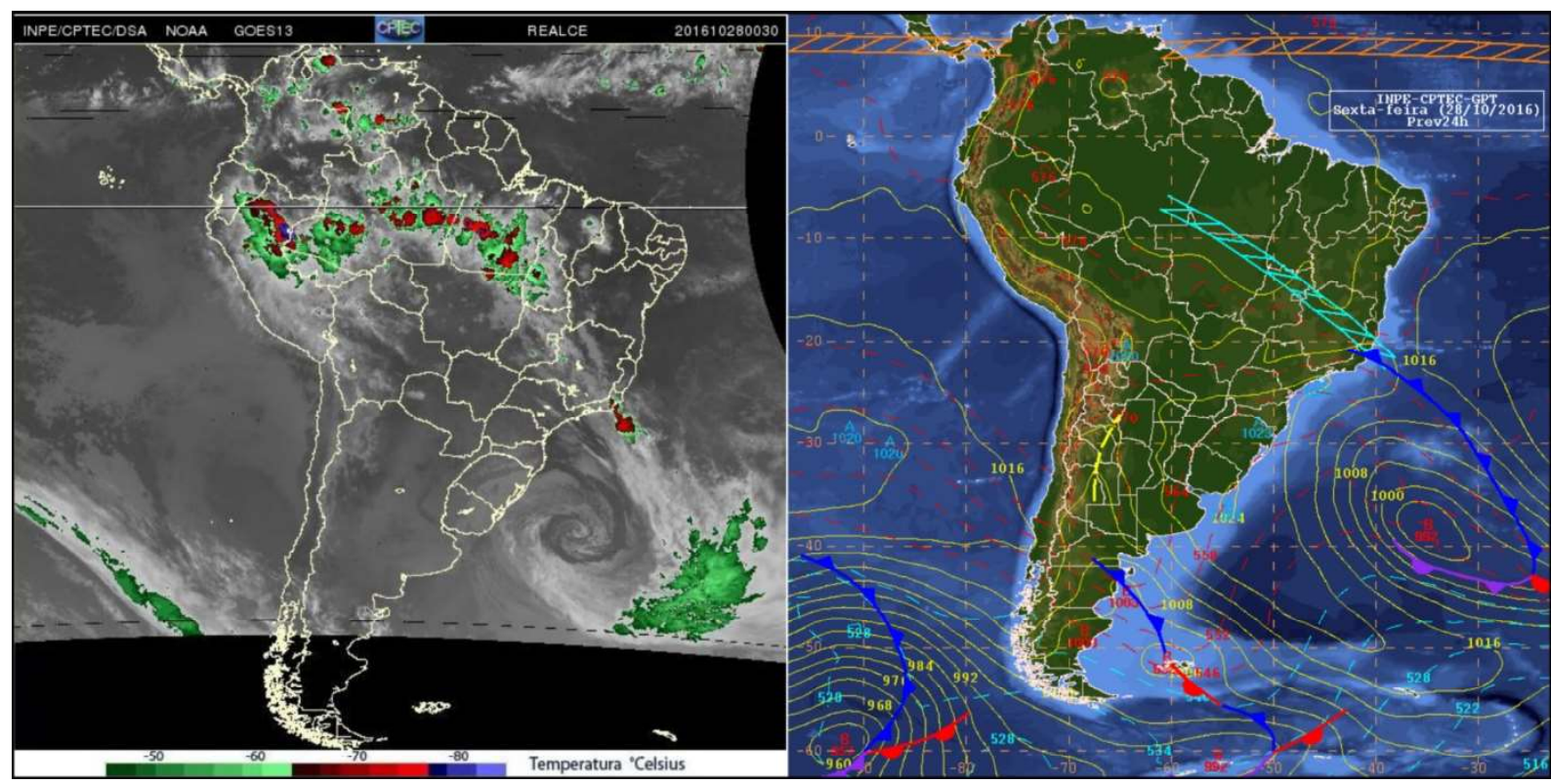

Figura 3 - Imagem do satélite Goes 16 e carta sinótica do dia 28 de outubro de 2016, (CPTEC, 2016).

A maré meteorológica estudada corresponde a um evento de curto prazo, que ocasionou inundações e erosão costeira. As marés meteorológicas positivas estão relacionadas a ciclones no oceano Atlântico sobre a plataforma continental, os mesmos movem-se em direção a costa e podem permanecer na região por dias, gerando ondas e ventos de alta intensidade (MAIA; CALLIARI; NICOLODI, 2016).

A queda na pressão atmosférica registrada pela boia Rio Grande teve início às 0:00 hs de 26/10, atingindo um mínimo, 995,25 milibar às 16:00 hs de 27/10 (FIGURA 4). Na costa, a queda na pressão atmosférica pode durar 48 hs em eventos desse tipo, com o valor mínimo de 954 milibar (HUBBERT; MCINNES, 1999). Segundo a teoria do barômetro inverso, a queda de 1 milibar na pressão atmosférica corresponde a uma elevação de $1 \mathrm{~cm}$ no nível médio do mar (BENAVENTE; DEL-RÍO; MARTÍNEZ-DEL-POZO, 2006). A passagem de sistemas de baixa pressão, como o registrado no evento, são associados às marés meteorológicas (ŁABUZ, 2014). No evento ocorreu uma queda máxima de 31 milibares, promovendo uma subida de $31 \mathrm{~cm}$ no nível médio do mar. $\mathrm{O}$ aumento na pressão ocorreu ainda no dia $27 / 10$ às $18: 00 \mathrm{hs}$, chegando ao valor máximo, 1026 às $12: 00$ hs de 29/10. A pressão retornou ao valor médio ao final do dia 30/10.

As direções dos ventos registradas em Tramandaí indicam que o evento teve início com a mudança da direção às 21:00 hs de 26/10 em Tramandaí para a direção Norte-Noroeste (NNW), com posterior estabilização na direção Oeste-Sudoeste (WSW) às 1:00 hs de 27/10. Essa direção manteve-se até as 10:00 hs de 29/10, com o vento Nordeste (NE) retornando às 3:00 hs de 30/10 (FIGURA 5).

A estação situada em Torres registrou alteração na direção dos ventos de Sul (S) às 2:00 hs de 27/10. A partir dessa hora, ocorreram variações nas direções, que se estabilizaram às 14:00 hs de 27/10 na direção WSW. Essa direção manteve-se até as 4:00 hs de 29/10 com a mudança para a direção Norte-Noroeste (NNW), que se manteve até as 9:00 hs do mesmo dia. A partir dessa hora, houve mudança da direção e a estabilização ocorreu às 11:00 hs de 30/10 nas direções Norte-Nordeste (NNE), (FIGURA 5). 


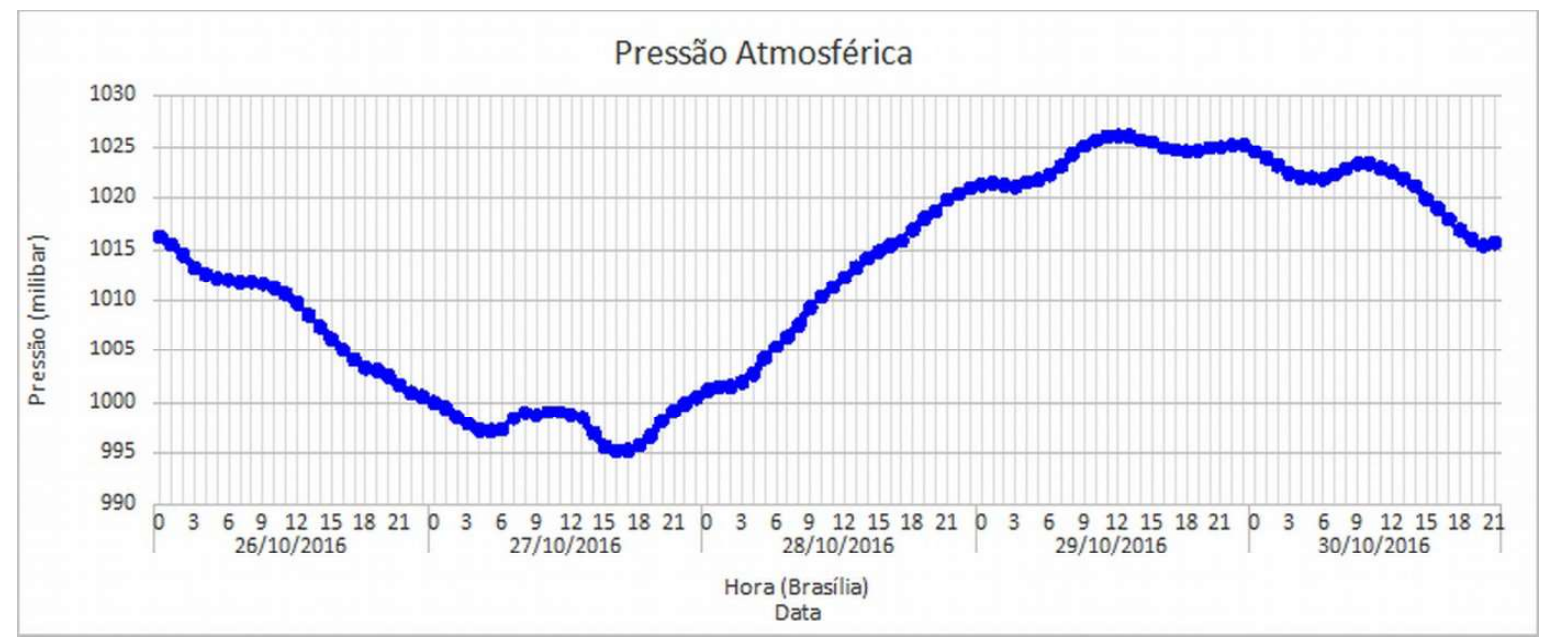

Figura 4 - Pressões atmosféricas registradas na boia 69153 - PNBOIA.

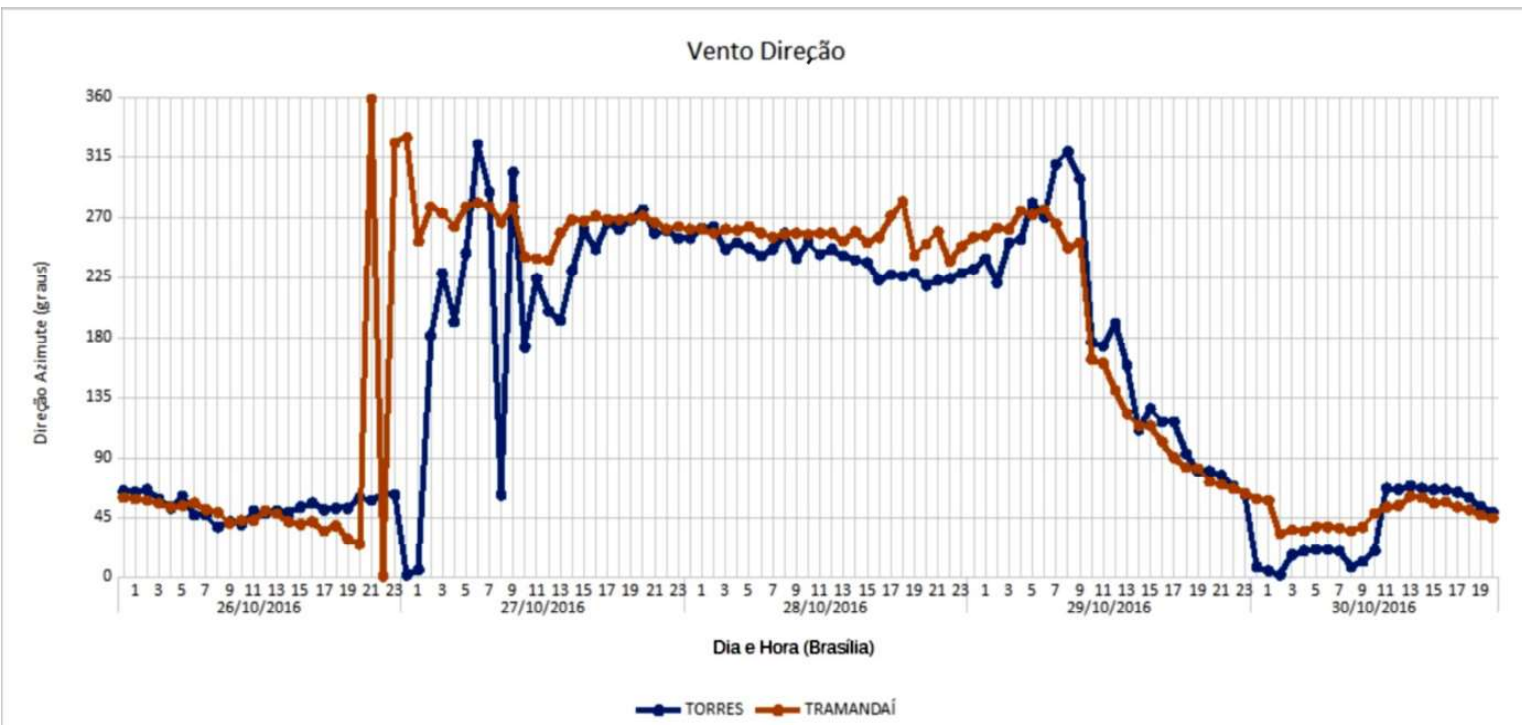

Figura 5 - Direções dos ventos registrados nas estações de Tramandaí e Torres.

Conforme observado na FIGURA 5, o ápice do evento ocorreu no dia 28/10. O mesmo teve início com a estabilização do vento na direção WSW por mais de 24 horas. Embora os ventos registrados pelas estações meteorológicas na costa venham do quadrante oeste, é provável que na região geradora das ondas, os ventos do quadrante sul tenham ocorrido com maior intensidade. Os ventos de $\mathrm{S}$ favorecem o empilhamento de água na costa do RS pelo transporte de Ekman. No hemisfério sul, ventos paralelos à costa, provenientes do quadrante $\mathrm{S}$, induzem um transporte de água em direção ao continente. Como a costa é impermeável, a água vai se acumulando, ocasionando sobre elevação no nível do mar, ou seja, uma maré meteorológica positiva (MELO FILHO, 2017).

A alteração na direção do vento incidente foi acompanhada pelo aumento nas velocidades médias registradas pelas estações meteorológicas. As velocida- des médias máximas registradas, a partir da mudança na direção dos ventos em ambas estações, ocorreram em 27/10 às 16:00 hs em Tramandaí (42 km/h) e às 21:00 hs em Torres (30 km/h), (FIGURA 6). As velocidades superiores a $20 \mathrm{~km} / \mathrm{h}$ ocorreram até 28/10 às 16:00 hs em Tramandaí e às 18:00 hs em Torres.

As rajadas também tiveram acréscimos em suas velocidades a partir do dia 27/10. A incidência de ventos com maior velocidade média e fortes rajadas na direção WSW promoveram condições para a sobre elevação do nível médio do mar. As velocidades máximas das rajadas foram de $93 \mathrm{~km} / \mathrm{h}$ às 15:00 hs em Tramandaí e $64 \mathrm{~km} / \mathrm{h}$ às 18:00 hs em Torres (FIGURA 7). As rajadas superiores aos $30 \mathrm{~km} / \mathrm{h}$ ocorreram até o final do dia 28/10. Eventos desse tipo podem produzir rajadas com velocidades de até $160 \mathrm{~km} / \mathrm{h}$, como registrado no noroeste da Austrália (HUBBERT; MCINNES, 1999). 


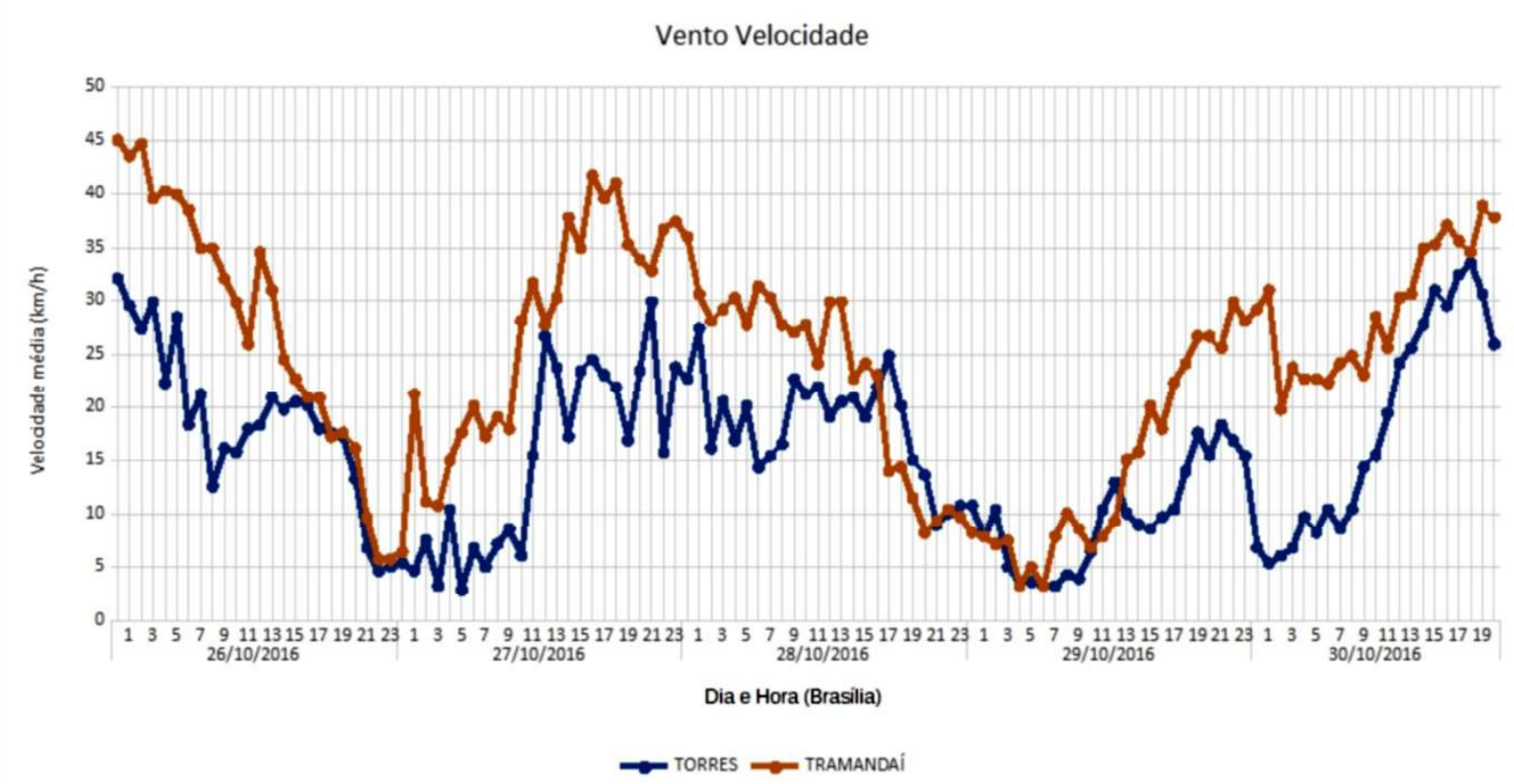

Figura 6 - Velocidades máximas dos ventos registrados nas estações de Tramandai e Torres.

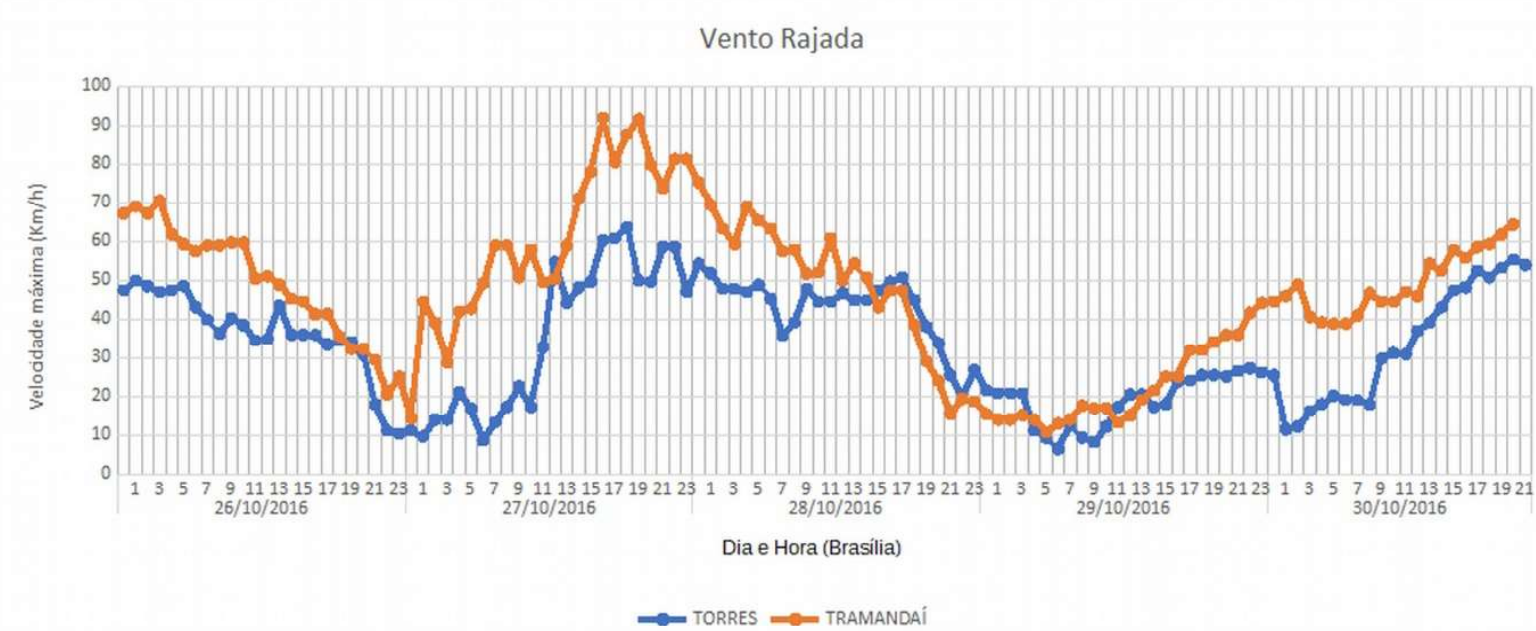

Figura 7 - Velocidades máximas das rajadas registradas nas estações de Tramandai e Torres.

As ondas incidentes na costa do RS tiveram as suas direções alteradas de $\mathrm{N}$ e $\mathrm{L}$ para NNW às 6:00 hs de 27/10 (FIGURA 8). Posteriormente, a direção variou entre Oeste Noroeste (WNW) e $\mathrm{S}$ até as 0:00 hs de 29/10. A partir desse horário, a direção manteve-se entre S e Sudeste (SE) até as 11:00 hs de 30/10.

O evento foi potencializado pela elevação nas alturas significativas e máxima das ondas em águas profundas. O aumento na altura significativa da onda é um grande contribuidor para a elevação no nível de água na costa (HOEKE; MCINNES; O'GRADY, 2015).
$\mathrm{O}$ aumento na altura significativa pode se estender por mais de 30 horas (ŁABUZ, 2014). A altura significativa das ondas aumentou a partir das 5:00 hs de 27/10, atingindo $9,5 \mathrm{~m}$ às 7:00 hs do dia 28/10. Outros picos de altura foram registrados no mesmo dia às 12:00 hs $(9,3$ m), $16: 00$ hs $(8,8 \mathrm{~m}), 21: 00$ hs $(7,9 \mathrm{~m})$ e $22: 00$ hs $(7,8$ m) (FIGURA 9). A altura significativa só atingiu valores inferiores a 4,00 m às 17:00 hs de 29/10. Próximo à costa, a altura significativa superou os $5 \mathrm{~m}$, e manteve-se superior a $3 \mathrm{~m}$ por mais de $48 \mathrm{hs}$ (OLIVEIRA; SIMÕES; CALLIARI; GAUTÉRIO, 2019). 


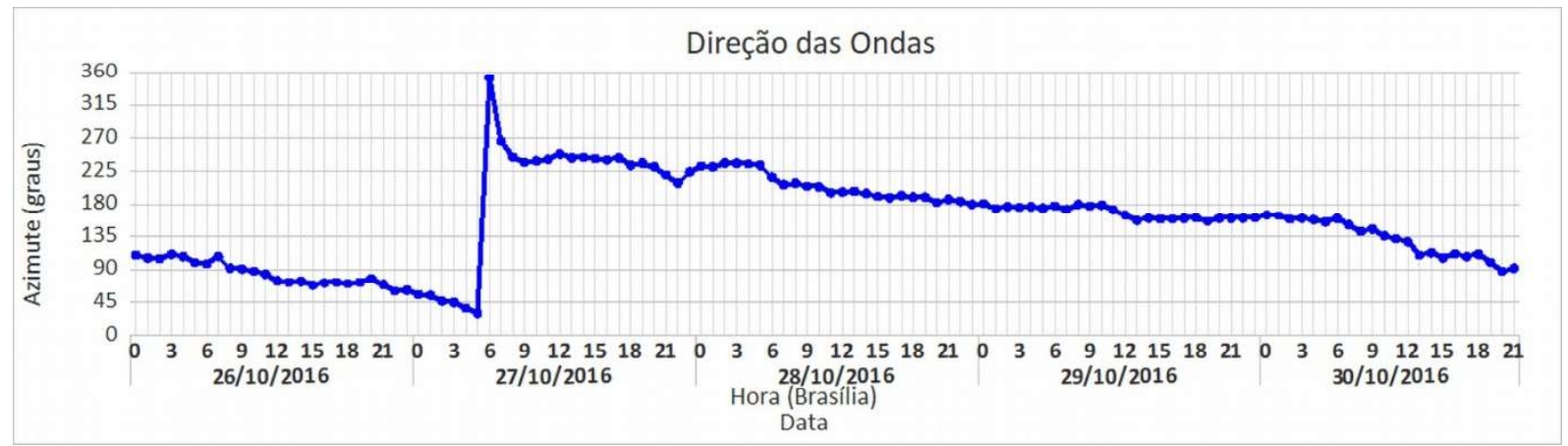

Figura 8 - Direções médias das ondas registradas na boia 69153 - PNBOIA.

Na FIGURA 9 observa-se uma tendência no aumento das alturas máximas das ondas, esse aumento teve início às 6:00 hs de 27/10. A altura máxima registrada, $14,8 \mathrm{~m}$, ocorreu às 11:00 hs de 28/10. Os picos de alturas máximas foram registrados no mesmo dia às 21:00 hs $(13,8 \mathrm{~m})$ e às $5: 00 \mathrm{hs}(12,4 \mathrm{~m})$ de $29 / 10$. O retorno das alturas máximas à tendência média aconteceu às 17:00 de 29/10.
A partir do dia 27/10 houve incremento aproximado de $8 \mathrm{~s}$ no período de pico das ondas. O aumento nos períodos de pico registrados tiveram início a partir das 16:00 hs de 27/10, estabilizando-se às 6:00 hs de 28/10 em, aproximadamente, $15 \mathrm{~s}$. O período de pico máximo $(16,7 \mathrm{~s})$ foi observado às 19:00 hs do dia 28/10. Diferente dos demais parâmetros descritos, os períodos de pico mantiveram-se elevados, superiores a 12 s, após o dia 29/10 (FIGURA 10).

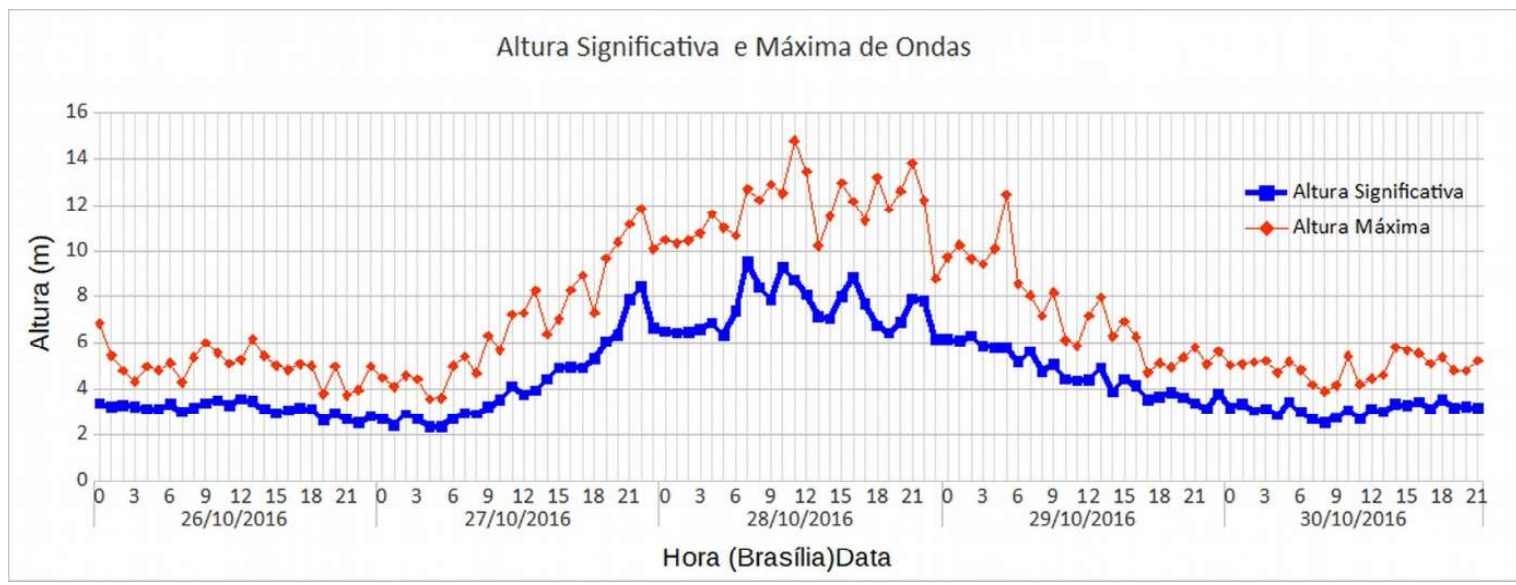

Figura 9 - Alturas significativas e máxima das ondas registradas na boia 69153 - PNBOIA.

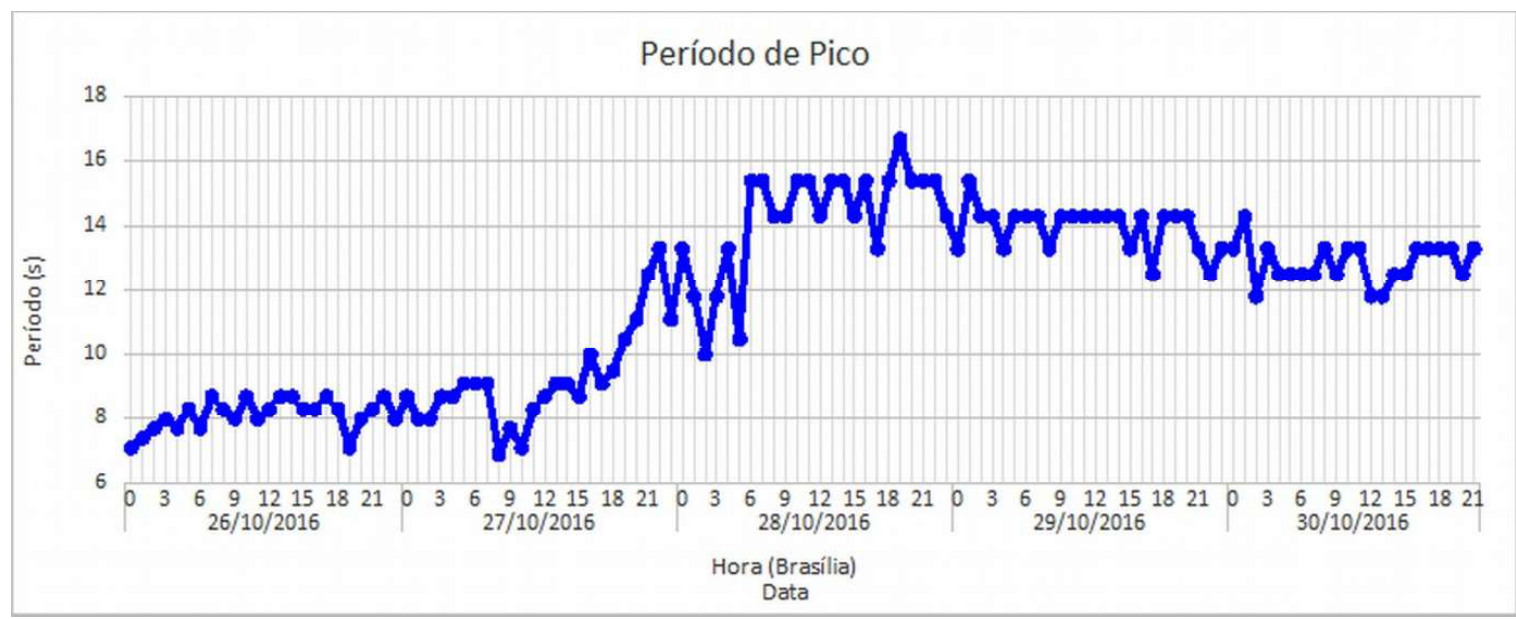

Figura 10 - Periodos de picos registrados na boia 69153 - PNBOIA. 
O aumento no nível da desembocadura da Laguna de Tramandaí teve início no dia 27/10 e foi ocasionado pela entrada de águas oceânicas na mesma. A elevação teve início às 8:00 hs de 27/10, chegando ao nível máxi- mo $(1,13 \mathrm{~m})$ às 9:00 hs de 28/10. Esse nível manteve-se até as 13:00 hs do mesmo dia, onde a queda teve início, chegando ao nível médio somente às 4:00 hs de 30/10 (FIGURA 11).

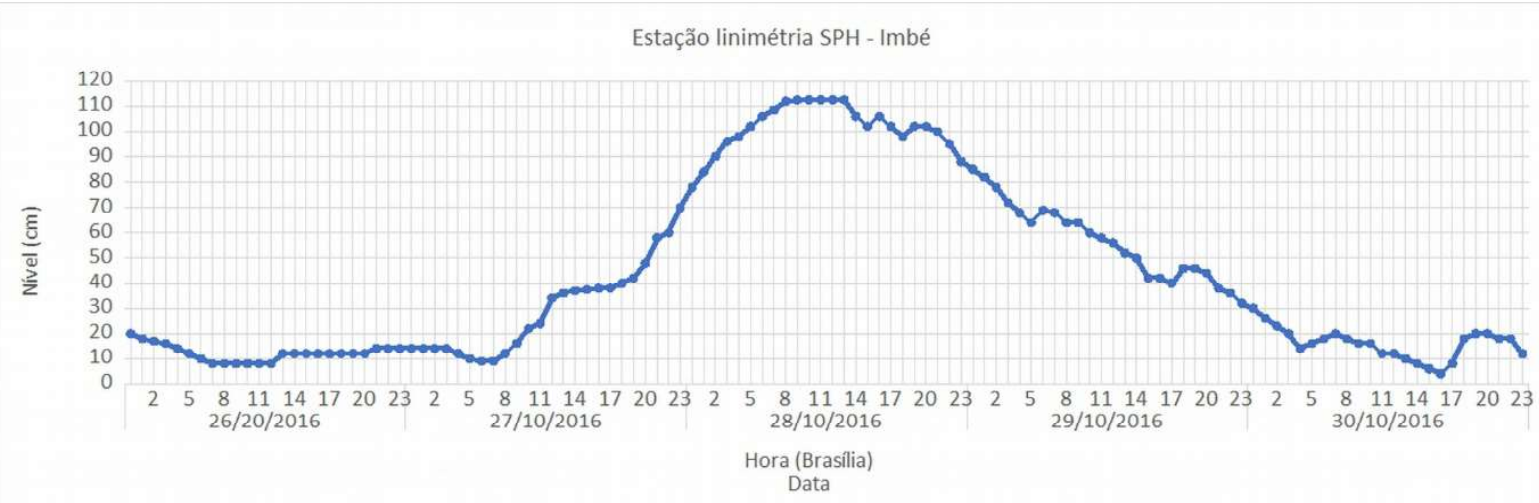

Figura 11 - Nivel do Rio Tramandai, em centímetros, registrado pela estação linimétrica da SPH em Imbé.

Na TABELA 1 estão descritas as coordenadas das altitudes inundadas identificadas nas fotografias e vídeos da maré meteorológica. Os pontos da tabela correspondem as maiores altitudes inundadas identificadas nos municípios da área de estudo.

De acordo com a TABELA 1 foram inundadas áreas com altitudes médias de 2,00 m. Inundações nessa altitude afetam os campos de dunas e as áreas pantanosas (DARSON; ASMATH; JEHU, 2013). Um efeito semelhante foi observado por MAIA, CALLIARI e NICOLODI(2016) na costa sul do RS e por GUIMARÃES, FARINA, TOLDO Jr., DIAZ-HERNANDEZ e AKHMATSKAYA (2015) em Tramandaí e Imbé. As imagens da maré meteorológica demonstraram que a primeira rua paralela ao cordão de dunas frontais foi inundada em quase todos os balneários estudados. O acesso das águas oceânicas se deu, principalmente, através de sangradouros. Nos balneários que tiveram suas dunas subtraídas para a construção de calçadões, as ondas atingiram seus níveis ocasionando inundações nas ruas adjacentes, como demonstrado na FIGURA 12.

Tabela 1: Locais de maiores altitudes inundados em 28 de outubro de 2016.

\begin{tabular}{|c|c|}
\hline Municípios & Coordenadas do ponto de máxima altitude inundada (AI) \\
\hline $\begin{array}{l}\text { Palmares do Sul } \\
\text { Centro }\end{array}$ & Lat: $-30^{\circ} 20^{\prime} 17^{\prime \prime} \mid$ Long: $-50^{\circ} 16^{\prime} 01 ”$ AI: $2,10 \mathrm{~m}$ \\
\hline $\begin{array}{l}\text { Cidreira } \\
\text { Centro }\end{array}$ & Lat: $-30^{\circ} 10^{\prime} 55^{\prime \prime} \mid$ Long: $-50^{\circ} 12^{\prime} 19 ” \mathrm{AI}: 2,15 \mathrm{~m}$ \\
\hline $\begin{array}{l}\text { Tramandaí } \\
\text { Centro }\end{array}$ & Lat: $-29^{\circ} 59^{\prime} 27^{\prime \prime} \mid$ Long: $-50^{\circ} 07^{\prime} 32^{\prime}$ | AI: 2,00 m (Fig. 11) \\
\hline \multirow{2}{*}{ Imbé } & Lat: $-29^{\circ} 58^{\prime} 42^{\prime \prime} \mid$ Long: $-50^{\circ} 07^{\prime} 31^{\prime \prime}$ AI: $0,60 \mathrm{~m}^{*}$ \\
\hline & Lat: $-29^{\circ} 58^{\prime} 05^{\prime \prime} \mid$ Long: $-50^{\circ} 06^{\prime} 57^{\prime \prime} \mid$ AI: 2,00 m (Fig. 12) \\
\hline $\begin{array}{l}\text { Osório } \\
\text { Mariápolis }\end{array}$ & Lat: $-29^{\circ} 52^{\prime} 13^{\prime \prime} \mid$ Long: $-50^{\circ} 04^{\prime} 11^{\prime \prime} \mathrm{AI}: 2,45 \mathrm{~m}$ \\
\hline Xangri-lá & Lat: $-29^{\circ} 47^{\prime} 44^{\prime \prime} \mid$ Long: $-50^{\circ} 01^{\prime} 54^{\prime \prime} \mathrm{AI}: 2,50 \mathrm{~m}$ \\
\hline Capão da Canoa & Lat: $-29^{\circ} 45^{\prime} 26^{\prime \prime} \mid$ Long: $-50^{\circ} 00^{\prime} 41^{\prime \prime}$ AI: $2,00 \mathrm{~m}$ \\
\hline Arroio do Sal & Lat: $-29^{\circ} 33^{\prime} 03^{\prime \prime} \mid$ Long: $-49^{\circ} 53^{\prime} 10^{\prime \prime} \mathrm{AI}: 2,15 \mathrm{~m}$ \\
\hline $\begin{array}{l}\text { Torres } \\
\text { Praia Grande }\end{array}$ & Lat: $-29^{\circ} 20^{\prime} 07^{\prime}$ | Long: $-49^{\circ} 43^{\prime} 18^{\prime} " \mid$ AI: 2,50 (Fig. 12) \\
\hline
\end{tabular}

*OBS: Estação Hidrológica de Imbé (SPH). Nesse ponto há um marco geodésico que, durante o evento, esteve submerso, a altitude inundada corresponde a altitude ortométrica do marco. 
Os balneários mais impactados (FIGURA 13) foram os situados nas altitudes mais baixas na área de estudo, os mesmos encontram-se próximos à desembocadura da Laguna de Tramandaí e do Rio Mampituba. Nas regiões estuarinas, como as citadas, as regiões a montante são as mais vulneráveis aos efeitos de tempestades e aumento do nível do mar, essas regiões também são vulneráveis à descarga fluvial (MCGUIGAN; WEBSTER; COLLINS, 2015). Regiões topograficamente baixas são muito vulneráveis às marés meteorológicas, inundações superiores a 1 $\mathrm{m}$ são uma ameaça em potencial às propriedades situadas à frente da praia (DARSON; ASMATH; JEHU, 2013).

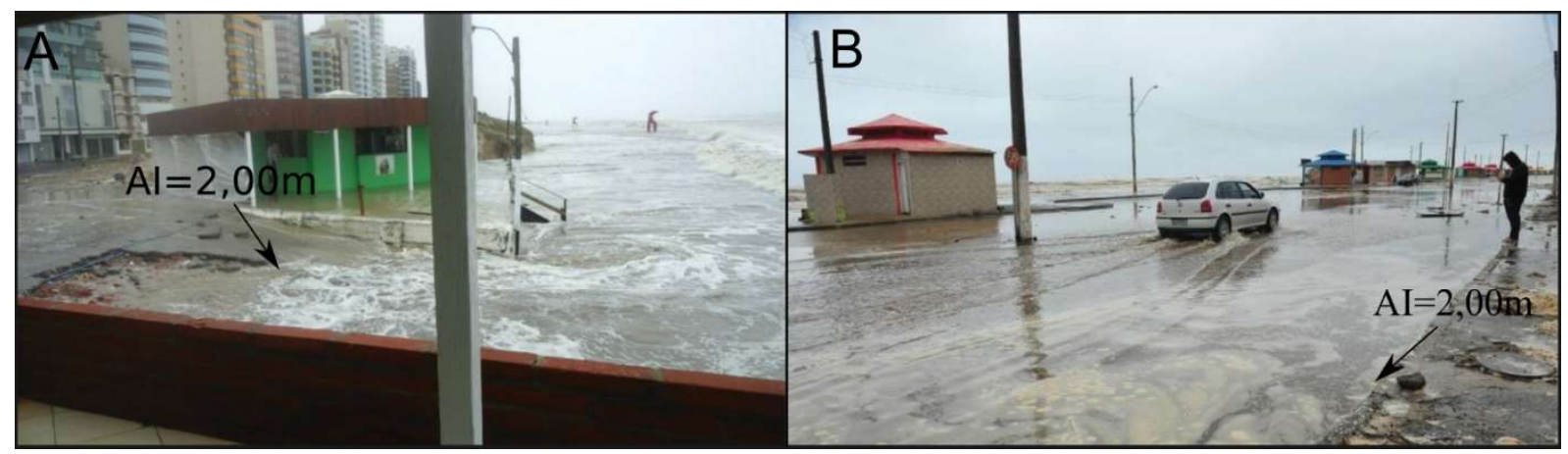

Figura 12 - Inundação próxima ao calçadão situado no Centro de Tramandai (A), (modificado de O Sul, 2016). Avenida Beira Mar, Balneário Imbé (B), (modificado de Souza, 2016). AI corresponde à altitude inundada.

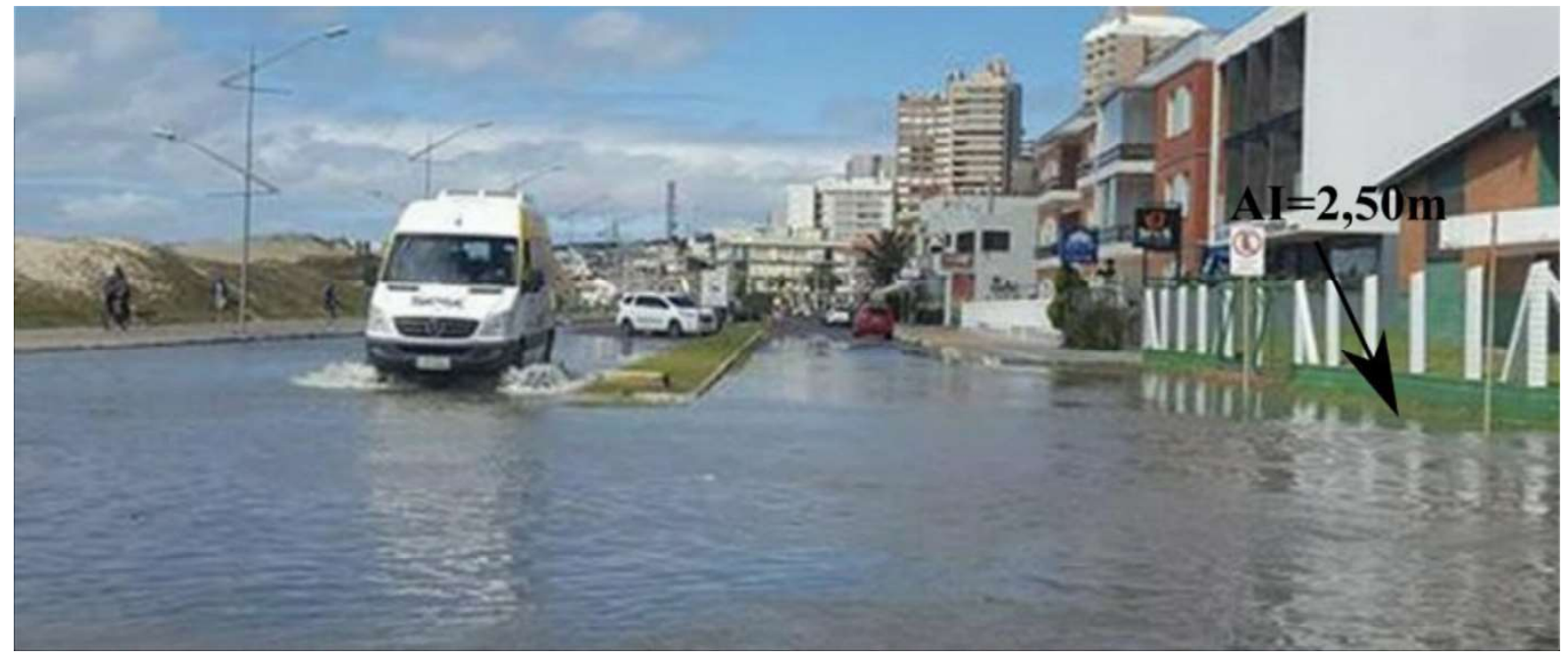

Figura 13 - Avenida Beira Mar inundada no balneário Praia Grande (Torres), (Soares, 2016).

A reconstituição de marés meteorológicas permite identificar e quantificar as áreas de risco (RAJI; DEL RÍO; GRACIA; BENAVENTE, 2011). Modelos digitais de superfícies, produzidos com dados LIDAR, possibilitam a construção de mapas realísticos das regiões inundadas, visto que o LIDAR produz uma grande densidade de pontos sobre a área de estudo. A grande precisão planialtimétrica conferida pelo LIDAR permite, até mesmo, o mapeamento de áreas suscetíveis a inundações provocadas por marés meteorológicas inferiores a $1 \mathrm{~m}$ (WEBSTER; FORBES; DICKIE; SHREENAN, 2004).

A altitude inundada, quando sobreposta em modelos digitais de superficies, indicam as áreas potencialmente vulneráveis às inundações, as menores altitudes são as mais vulneráveis a elevações do nível do mar (MAIA; CALLIARI; NICOLODI, 2016). A trajetória percorrida pelas águas durante as inundações são sensíveis à morfologia local (HOEKE; MCINNES; O'GRADY, 2015). Essas informações podem ter aplicação no planejamento e gerenciamento do uso do solo nas áreas costeiras (RAJI; DEL RÍO; GRACIA; BENAVENTE, 2011). Mapas de inundação são uma poderosa ferramenta para o planejamento de estratégias mitigadoras de danos em zonas costeiras (DARSON; ASMATH; JEHU, 2013). Nas FIGURAS 14, 15 e 16 são apresentadas as imagens hipsométricas, com as áreas inundadas, dos balneários mais impactados pela maré meteorológica: Zona A (Cidreira), Barra (Tramandaí), Balneário Imbé (Imbé) e Praia Grande (Torres). 
Inundação e Erosão na Costa Norte do Rio Grande do Sul - Brasil. Estudo de Caso: A Maré Meteorológica

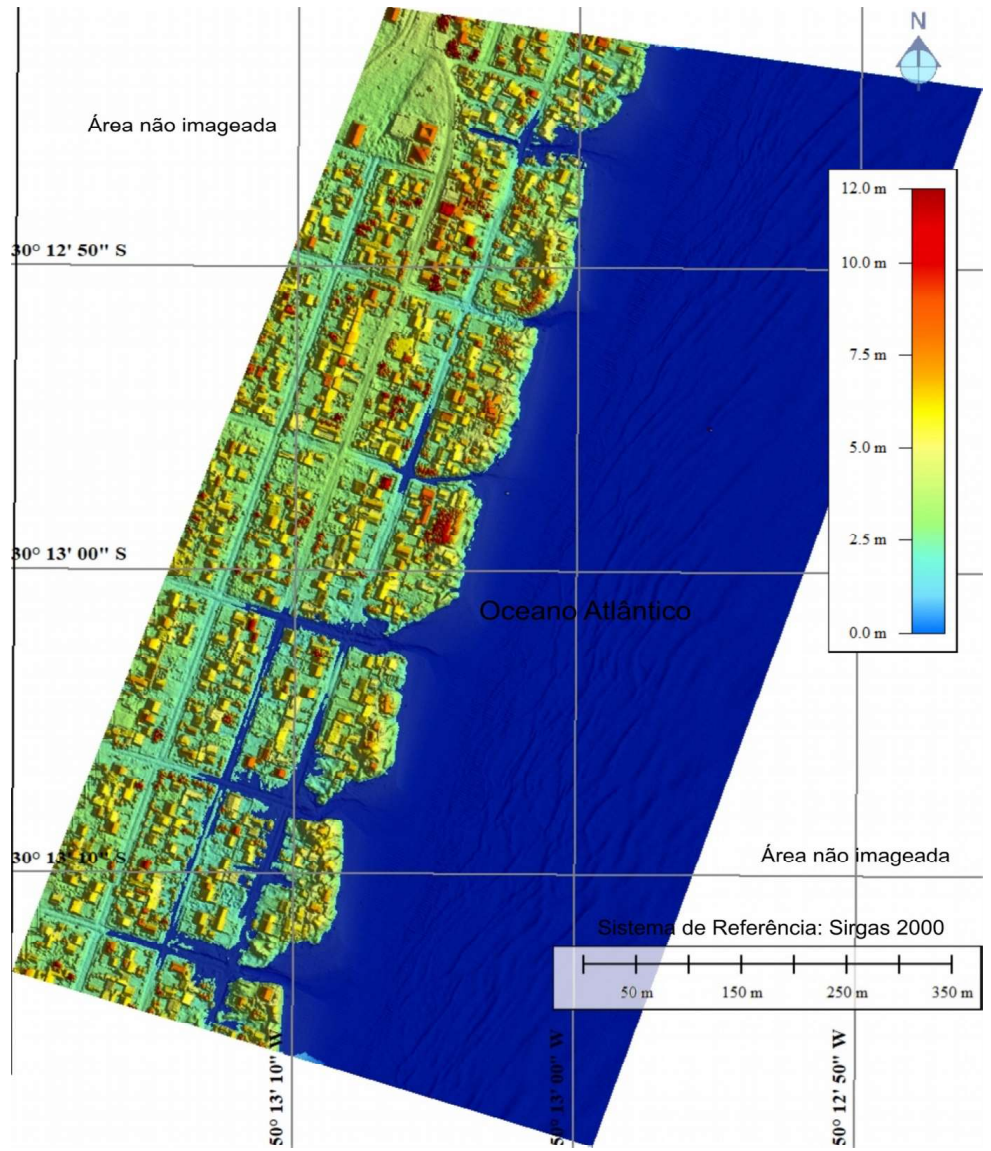

Figura 14 - Imagem LIDAR da área inundada (azul-escuro) no balneário Zona A em Cidreira - RS.

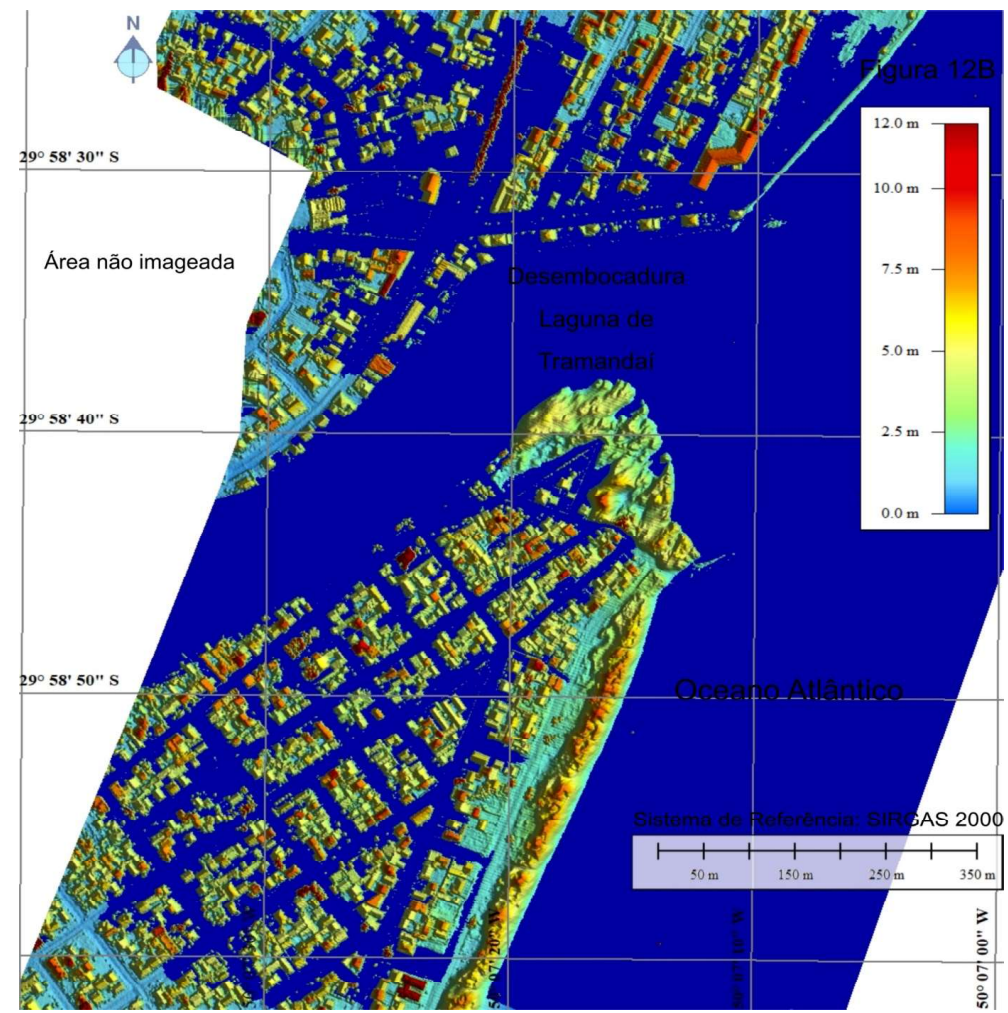

Figura 15 - Imagem LIDAR da área inundada (azul-escuro), ao sul da desembocadura o balneário Barra e ao norte Balneário Imbé. 


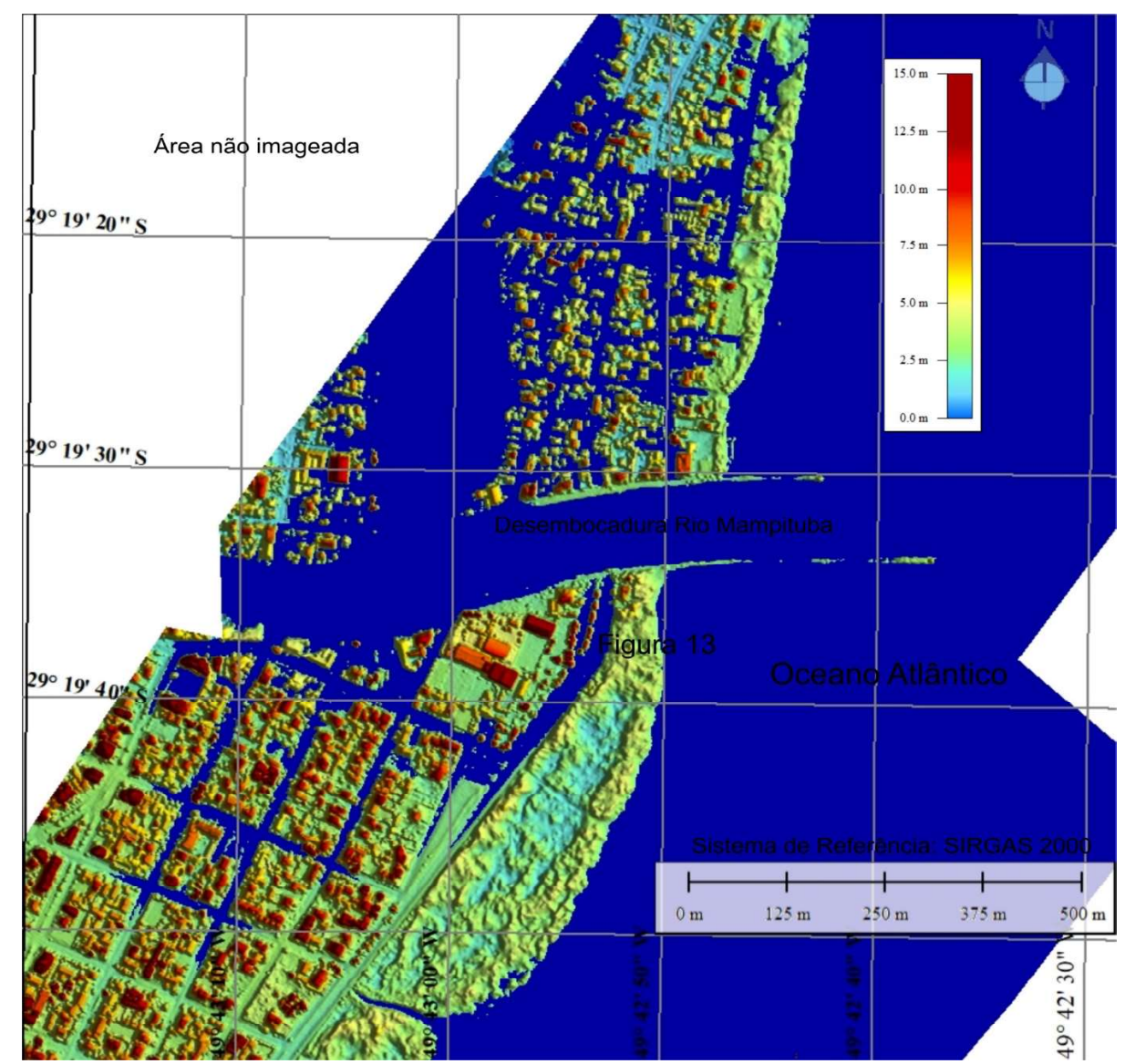

Figura 16 - Imagem LIDAR da área inundada (azul-escuro) na Praia Grande (Torres).

Nos balneários com dunas frontais segmentadas, as inundações ocorreram pela entrada das águas a partir dos sangradouros, esse cenário corresponde ao mais frequente na área de estudo (FIGURA 14). Em alguns pontos da área, ocorrem 10 sangradouros por quilômetro. Sangradouros não naturais, criados pela drenagem urbana de ruas orientadas perpendicularmente às dunas frontais, foram os principais responsáveis pelas inundações no interior dos balneários degradados. Este cenário é uma das consequências da urbanização sem planejamento, uma alternativa para impedir a formação desses sangradouros é a criação de uma política de ocupação do solo urbano, articulada com projetos de drenagem urbana nessas áreas.

A propagação da água nos modelos digitais de superfície é fortemente influenciada pela topografia do terreno (HÖFFKEN; VAFEIDIS; MACPHERSON; DANGENDORF, 2020). Como demonstrado na FIGURA 15, Barra e Balneário Imbé situam-se na região mais suscetível a inundações promovidas por maré meteorológica na área de estudo. Pela inexistência de dunas frontais, em Balneário Imbé, a água dispersa-se sobre o calçadão invadindo as ruas (GUIMARÃES; FARINA; TOLDO Jr.; DIAZ-HERNANDEZ; AKHMATSKAYA, 2015). As inundações estenderam-se por, aproximadamente, 500 $\mathrm{m}$ ao norte e ao sul da desembocadura, impactando as primeiras quadras dos balneários. Essa região está situada na menor altitude da área de estudo, sendo suscetíveis à inundações por águas oceânicas durante marés meteorológicas, e por continentais em precipitações extremas. Próximo à desembocadura, dentro do estuário, as áreas de baixas altitudes não protegidas por dunas frontais foram indicadas por GUIMARÃES, FARINA, TOLDO Jr., DIAZ-HERNANDEZ e AKHMATSKAYA (2015) como sendo muito vulneráveis às inundações.

O evento provocou uma elevação superior a $1 \mathrm{~m}$ no nível médio da desembocadura da Laguna de Tramandaí, o que ocasionou grandes inundações nos balneários Barra (Tramandaí) e Balneário Imbé (FIGURA 15). Na FIGURA 12 foram apresentadas imagens de ruas inundadas adjacentes à desembocadura. No Balneário Imbé, o calçadão conferiu um certo grau de proteção à costa, porém foi parcialmente destruído (FIGURA 17). Danos em quebra mares e diques ocasionados por marés meteorológicas ocorrem devido aos efeitos combinados da elevação no nível do mar e de fortes ondas (STANEVA; WAHLE; KOCH; BEHRENS; FENOGLIO-MARC; STANEV, 2016). 


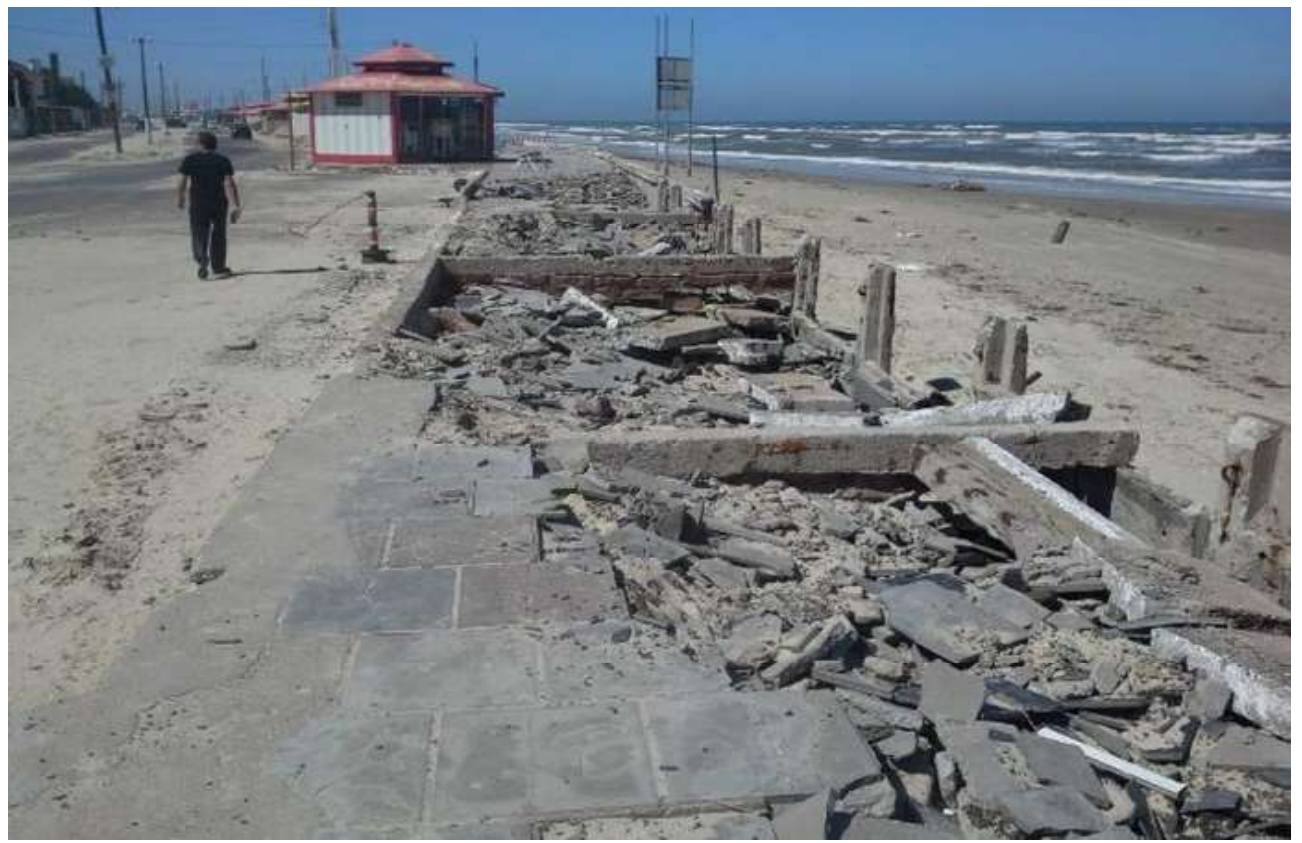

Figura 17 - Calçadão e mureta de contenção parcialmentes destruídos em Balneário Imbé.

Verificaram-se grandes impactos na Praia Grande (FIGURAS 13 e 16). O aumento no nível do Rio Mampituba, assim como na desembocadura da Laguna de Tramandaí, provocou grandes inundações, que se estenderam também por, aproximadamente, $500 \mathrm{~m}$ ao norte e ao sul da desembocadura do rio. O acesso das águas a partir de caminhos entre as dunas também contribuiu para a inundação das ruas adjacentes. Nessa região, os impactos da inundação, como a erosão das dunas foi menor devido a maior altitude média do município de Torres. Processos erosivos são mais intensos em balneários abaixo da altitude média de $2 \mathrm{~m}$ (ŁABUZ, 2014).

Os volumes de sedimentos erodidos nas dunas frontais foram mensurados nos balneários Dunas Altas (Palmares do Sul) e Zona A (Cidreira). A escolha desses balneários se deu pelas suas morfologias extremas. Dunas Altas é um balneário com uma urbanização planejada, possui as maiores dunas frontais e a mais extensa praia subaérea da área de estudo. Zona Aé um balneário urbanizado sem planejamento, que teve parte das dunas frontais subtraídas e substituídas por edificações de baixo padrão construtivo, restando fragmentos do cordão dunar original. Diversos sangradouros formados pela drenagem urbana ocorrem em Zona A devido a impermeabilização do solo.

Na FIGURA 18 são apresentadas as bases das dunas frontais antes, medidas no modelo digital de superfície, e as escarpas erosivas após o evento. O recuo máximo na base da duna frontal medido foi de $5 \mathrm{~m}$ (Dunas Altas) e $15 \mathrm{~m}$ (Zona A). OLIVEIRA, SIMÕES, CALLIARI e
GAUTÉRIO (2019) ao analisar, para o mesmo evento, a retração da base da duna em seis balneários na costa do RS observaram recuos de $4 \mathrm{~m}$ a $21 \mathrm{~m}$. Recuo de 1,4 m na base da duna frontal já foi registrado na costa da Polônia durante marés meteorológicas, essa retração correspondeu a uma perda de $0,3 \mathrm{~m}^{3} / \mathrm{m}$ ( (LABUZ, 2014). O volume erodido, em Dunas Altas, foi de $424 \mathrm{~m}^{3} \mathrm{em}$ um trecho de $572 \mathrm{~m}$, correspondendo a $0,73 \mathrm{~m}^{3} / \mathrm{m}$. Já no balneário Zona A, o volume erodido foi de $2.842 \mathrm{~m}^{3} \mathrm{em}$ um trecho $803 \mathrm{~m}$, correspondendo a $3,54 \mathrm{~m}^{3} / \mathrm{m}$ (FIGURA 18). A praia subaérea mais extensa de Dunas Altas contribuiu para uma menor perda sedimentar.

Nas regiões preservadas, as dunas frontais forneceram uma boa proteção durante o evento, as mesmas funcionaram como barreiras que impediram a entrada das águas. A importância das dunas frontais na proteção contra marés meteorológicas foi descrita RAJI, DEL RÍO, GRACIA e BENAVENTE (2011) utilizando-se de uma metodologia semelhante à apresentada nesse trabalho. Conforme o mensurado em Dunas Altas, observações em campo confirmaram a menor retração e perda sedimentar nos balneários com dunas frontais preservadas. Isso pode ser explicado pelo maior percentual de cobertura vegetal na duna frontal. Na região ocorrem, em maior frequência, Blutaparon portulaciodes, Panicum racemosum e Senecio crassiflorus, essas espécies vegetais possuem raízes na forma de estolão, que ancoram os sedimentos e aumentam a resistência da duna a processos erosivos. 


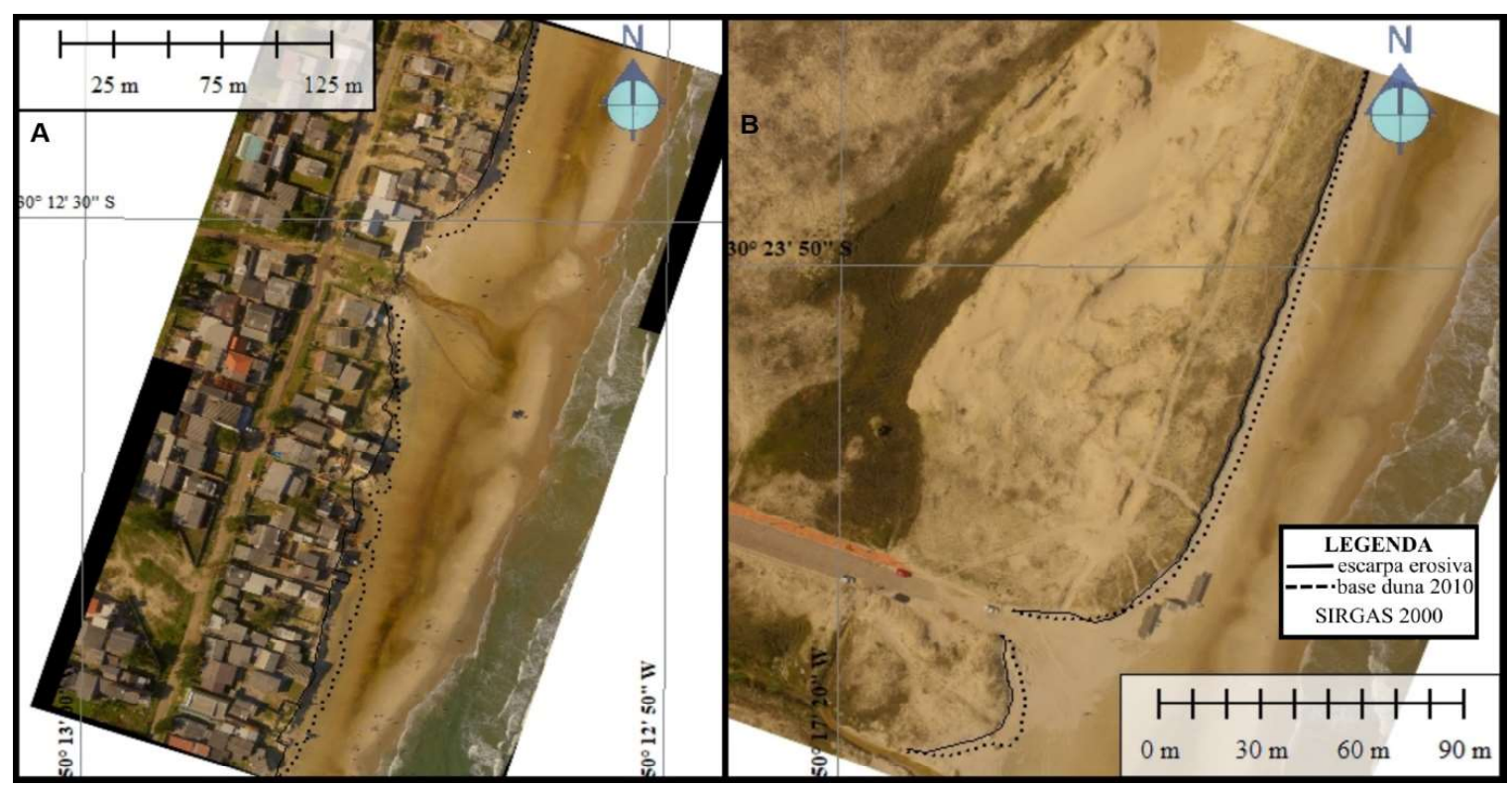

Figura 18 - Escarpa erosiva e antiga base da duna frontal dos balneários Zona A (esquerda - A) e Dunas Altas (direita - B).

Marés meteorológicas desempenham um importante papel na erosão das dunas, devido ao ataque das ondas no pé das dunas (SUANEZ; CANCOUËT; FLOC'H; BLAISE; ARDHUIN; FILIPOT; CARIOLET; DELACOURT; CSUANEZ, 2015). Em toda a área de estudo observou-se a formação de escarpas erosivas nas dunas frontais devido a ação das ondas, como o verificado no trecho imageado em Dunas Altas. Existe uma correlação entre a erosão das dunas e a altitude inundada, a erosão é observada quando a inundação ultrapassa o pé da duna (SUANEZ; CANCOUËT; FLOC'H; BLAISE; ARDHUIN; FILIPOT; CARIOLET; DELACOURT; CSUANEZ, 2015). Ao sul desse balneário verificou-se a formação das maiores escarpas erosivas na área de estudo, com mais de $4 \mathrm{~m}$ de altura (FIGURA 19).

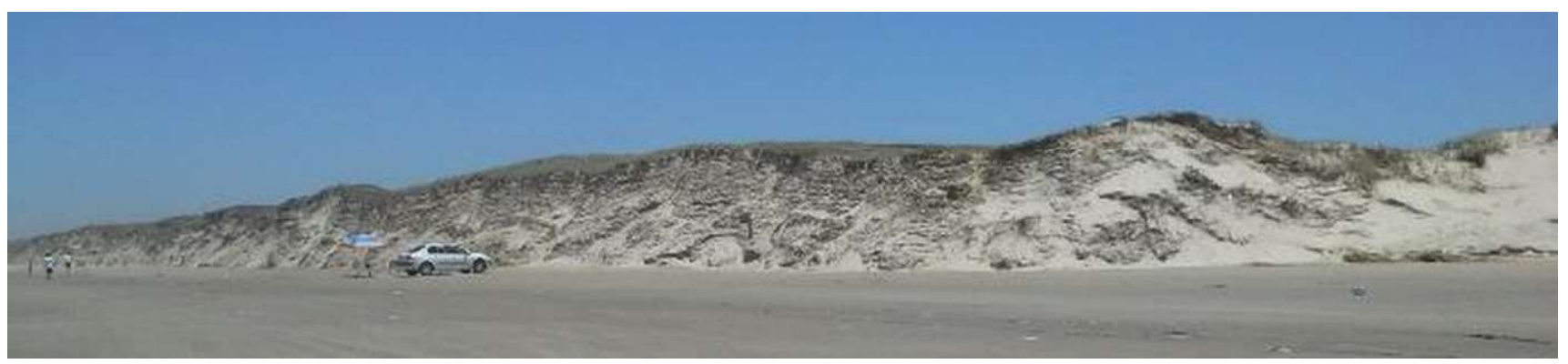

Figura 19 - Escarpa erosiva em Dunas Altas - Palmares do Sul.

O pequeno número de áreas impermeabilizadas, e a consequente preservação dos lençóis arenosos e regiões interdunas, contribuiu para a menor incidência de impactos nos balneários preservados. Essas regiões servem como área de amortecimento durante as marés meteorológicas, infiltrando as águas e desacelerando o fluxo em direção ao continente. A baixa impermeabilização do Balneário Dunas Altas é resultante de uma política urbana de ordenação e controle do uso do solo, que se trata do Plano Diretor do município, que promo- ve políticas de proteção e preservação do patrimônio natural (PALMARES DO SUL, 2006).

Em Palmares do Sul observa-se que os danos causados pela maré meteorológica foram mínimos devido a preservação da área assegurada pela legislação do local, a qual impede a ocupação por edificações na área de preservação permanente. Por outro lado, na área de estudo, existem diversos balneários urbanizados sem planejamento, com dunas frontais parcial ou totalmente removidas e com grande densidade de edificações perto 
da linha d'água. Os efeitos das marés meteorológicas são potencializados nestes locais, visto que os fragmentos eólicos remanescentes, não vegetados do cordão original, são facilmente erodidos pela ação das ondas. Assim como o observado por HÖFFKEN, VAFEIDIS, MACPHERSON e DANGENDORF (2020) na costa da Alemanha, os maiores danos provocados pelas inundações ocorreram nas áreas com maior densidade de edificações. Nos balneários Costa do Sol e Zona A, ambos no município de Cidreira, ocorreu o colapso de edificações situadas na primeira quadra urbanizada, sendo as construções de madeira as mais impactadas (FIGURA 20).

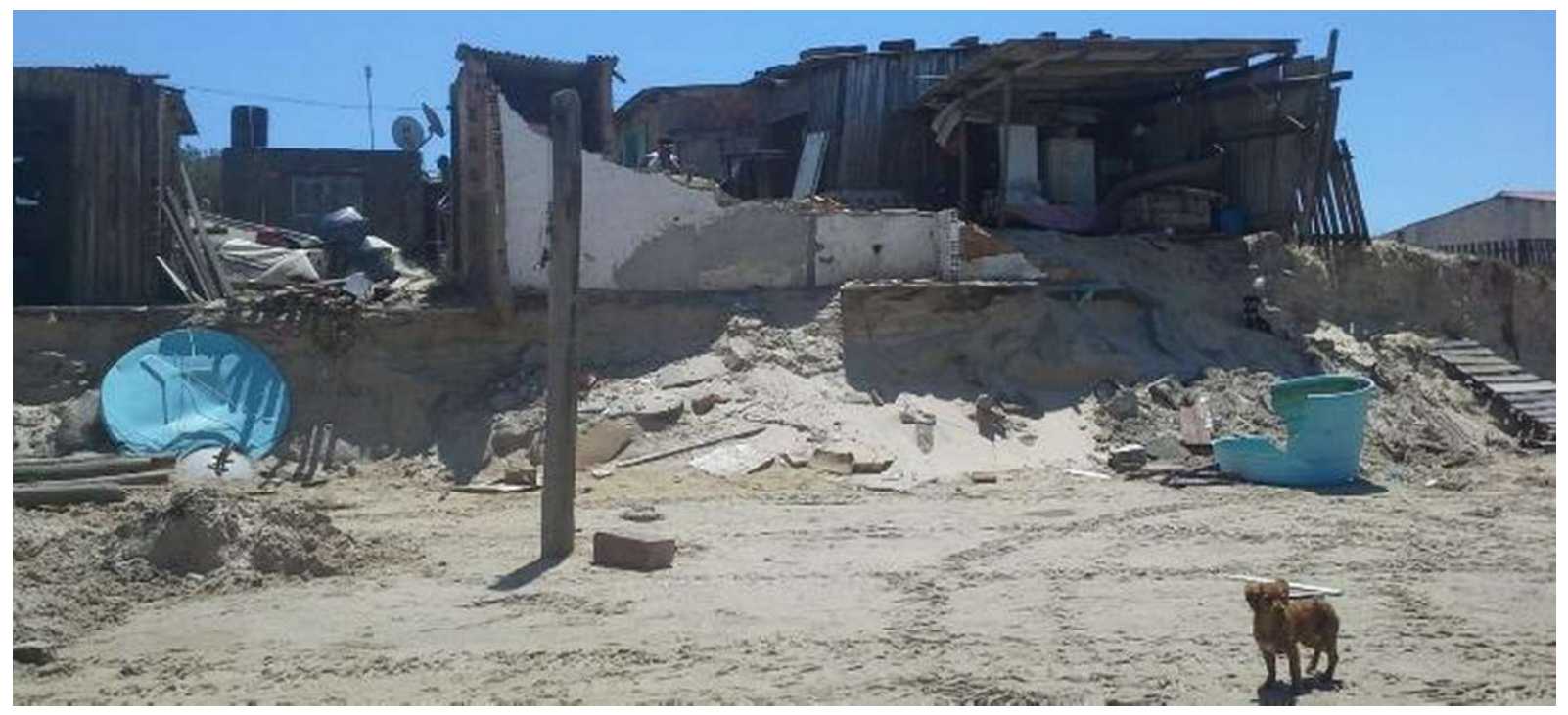

Figura 20 - Danos em edificações de madeira no balneário Zona A - Cidreira.

Este cenário que envolveu danos às edificações (FIGURA 20) foi intensificado devido às condições de falta de controle e ordenação do uso do solo. A ausência de plano diretor em Cidreira reflete-se nas condições de segurança das habitações, as quais são edificadas sobre as dunas frontais, consideradas área de preservação permanente (RIO GRANDE DO SUL, 2000).

A análise demonstrou que, durante as marés meteorológicas, as habitações localizadas sobre as dunas são as mais impactadas e oferecem maior risco à segurança de seus usuários. Além disso, tem-se o impacto ambiental causado pela implantação de edificações em uma área de preservação permanente, cuja proteção e conservação são de interesse coletivo. Os instrumentos legais para a proteção dessas áreas existem nas esferas federal, estadual e municipal.

A constituição federal enuncia que a Zona Costeira é patrimônio nacional e seu uso só pode ocorrer dentro de condições que garantam a preservação do meio ambiente (BRASIL, 1988). O Código Estadual do Meio Ambiente do RS descreve que a zona costeira é um espaço territorial especialmente protegido, objeto do Programa Estadual de Gerenciamento Costeiro, que tem como objetivo o controle do uso e da ocupação do solo (RIO GRANDE DO SUL, 2000). Na esfera municipal Palmares do Sul, Tramandaí, Capão da Canoa e Torres possuem Plano Diretor.

\section{CONCLUSÕES}

O evento teve início no dia 27/10/2016 com a alteração e estabilização da direção do vento na orientação WSW e com o aumento na altura significativa das ondas. As rajadas de vento de alta velocidade somaram-se ao cenário de maré meteorológica, aumentando a área inundada. No evento, altitudes acima de 2,00 $\mathrm{m}$ foram impactadas, sinalizando que mesmo áreas elevadas são suscetíveis, desde que próximas ao perfil ativo da praia.

A entrada de águas oceânicas na desembocadura da Laguna de Tramandaí e do Rio Mampituba promoveram grandes inundações nos balneários adjacentes, devido ao aumento em seu nível, que chegou a 1,3 m em Tramandaí. O fato da área de estudo ser amplamente habitada possibilitou que diversos registros em fotos e vídeos fossem realizados das áreas impactadas no evento. Tais registros foram de grande utilidade para a demarcação das áreas inundadas nos modelos digitais 
de superfície. A disponibilidade de dados cartográficos, de alta resolução planialtimétrica, é primordial para a delimitação das áreas suscetíveis e para a reconstrução dos impactos provocados pelas marés meteorológicas em áreas costeiras.

O pacote Simulate Water Level Rise/Flooding foi de grande utilidade para a reconstrução e mapeamento dos pontos inundados pela maré meteorológica. As simulações evidenciaram a proteção proporcionada pelas dunas frontais. As regiões interdunares conferem uma boa proteção também a costa, visto que desaceleram o avanço das águas pelo atrito com a vegetação e pela infiltração da água no solo. A preservação dessas áreas, conjuntamente com as dunas frontais, são importantes medidas preventivas para a redução dos efeitos das marés meteorológicas.

O aumento dos impactos devido a entrada de água por sangradouros também ficou evidente no estudo. No litoral norte do RS ocorrem muitos sangradouros formados pela drenagem urbana de ruas e em caminhos de pedestres sobre as dunas. Os mesmos permitem que as águas ingressem além de $200 \mathrm{~m}$ da base a sotavento das dunas frontais em diversos balneários. O planejamento dos balneários, com a consequente remoção desses sangradouros e reconstrução das dunas frontais, consiste em uma medida importante para prevenção de danos ocasionados pelas marés meteorológicas.

$\mathrm{O}$ aumento da área impermeabilizada também é responsável por elevar os impactos nos balneários durante as marés meteorológicas, visto que ocasionam o aumento no escoamento superficial e, consequentemente, aceleram processos erosivos. Quando ocorrem precipitações extremas, a impermeabilização diminui o tempo de concentração e potencializa a ação erosiva dos sangradouros.

Os balneários com edificações sobre no perfil ativo da praia (Zona A e Costa do Sol) são de grande suscetibilidade e o colapso das edificações em marés meteorológicas é inevitável nos mesmos. Espera-se que as imagens geradas possam ser utilizadas no planejamento dos balneários, para se minimizar os danos futuros das marés meteorológicas na magnitude estudada.

\section{REFERÊNCIAS BIBLIOGRÁFICAS}

ALMEIDA, L. E. S. B.; LIMA, S. F.; TOLDO Jr, E. E. (2006). Estimativa da capacidade de transporte de sedimentos a partir de dados de ondas. In: MUEHE, D. (org.). Erosão e progradação do litoral brasileiro. Ministério do Meio Ambiente, Brasília: p. 455-459.

ANDRADE, M. M.; TOLDO, E. E.; NUNES, J. C. R. Tidal and subtidal oscillations in a shallow water system in southern Brazil. Brazilian Journal of Oceanography, [s.l.], v. 66, n. 3, p.245-254, set. 2018. DOI: 10.1590/s1679-87592018017406603

ANGULO, R; LESSA, G; SOUZA, M. A critical review of midto late-Holocene sea-level fluctuations on the eastern Brazilian coastline. Quaternary Science Reviews, [s.l.], v. 25, n. 5-6, p.486-506, mar. 2006. DOI:10.1016/j.quascirev.2005.03.008

BARLETTA, R. C.; CALLIARI, L. J. Determinação da intensidade das tempestades que atuam no litoral do Rio Grande do Sul, Brasil. Pesquisas em Geociências, Porto Alegre, v. 28, n. 2, p.117-124, jun. 2001. DOI: 10.22456/1807-9806.20276

BENAVENTE, J.; DEL RÍO, L.; MARTÍNEZ-DEL-POZO, J. A. Coastal flooding hazard related to storms and coastal evolution in Valdelagrana spit (Cadiz Bay Natural Park, SW Spain). Continental Shelf Research, [s.l.], v. 26, n. 9, p.10611076, jun. 2006. DOI: $10.1016 /$ j.csr.2005.12.015

BLUE MARBLE GEOGRAPHICS. Simulate Water Level Rise/ Flooding. Disponível em: <https://www.bluemarblegeo. com/knowledgebase/global-mapper-21-1/Simulate_Water_ Level_Rise_Flooding.htm>. Acesso em 05 mai. 2020.

BRASIL. [Constituição (1988)]. Constituição da República Federativa do Brasil de 1988. Brasília, DF: Presidência da República, [2019]. Disponível em: <https://www.senado.leg.br/ atividade/const/con1988/con1988_06.06.2017/CON1988.pdf>. Acesso em: 10 ago. 2019.

BRASIL. Lei $n^{\circ} 10257$, de 10 de julho de 2001. Regulamenta os arts. 182 e 183 da Constituição Federal, estabelece diretrizes gerais da política urbana e dá outras providências. Lei $\mathrm{N}^{\circ} \mathbf{1 0 . 2 5 7}$, de 10 de Julho de 2001: Regulamenta os arts. 182 e 183 da Constituição Federal, estabelece diretrizes gerais da política urbana e dá outras providências.. Brasília, DF, Disponível em: $<$ http://www.planalto.gov.br/ccivil_03/leis/leis_2001/110257. htm>. Acesso em: 09 ago. 2019.

CALLIARI, L. J.; SILVA, R. P. Erosion processes associated to storm surge and washout along the south brazilian coastline. Journal of Coastal Research, [s.l.], v. 26, p. 1-7, 1998.

CALliARI, L. J.; PEREIRA, P. S.; DE OLIVEIRA, A. O.; FIGUEIREDO, S.A. Variabilidade das dunas frontais no litoral norte e médio do Rio Grande do Sul/Brasil. Gravel, Porto Alegre, p.15-30, nov. 2005. 
CALliARI, L. J.; TOZZI, H. A. M.; KLEIN, A. H. F. Beach morphology and coastline erosion associated with storm surges in southern Brazil - Rio Grande to Chuí, RS. Anais da Academia Brasileira de Ciências, [s.l.], v. 70, n. 2, p. 231-247, 1998.

CARDONA, O. D.; VAN AALST, M. K.; BIRKMANN, J.; FORDHAM, M.; MCGREGOR, G.; PEREZ, R.; PULWARTY, R. S.; SCHIPPER, E. L. F.; SINH, B. T. (2012). Determinants of risk: exposure and vulnerability. In: FIELD, C. B.; BARROS, V.; STOCKER, T. F.; QIN, D.; DOKKEN D. J.; EBI, K. L.; MASTRANDREA, M. D.; MACH, K. J.; PLATTNER, G. K.; AlLEN, S. K.; TIGNOR, M.; MIDGLEY, P. M. (org.). Managing the Risks of Extreme Events and Disasters to Advance Climate Change Adaptation. Cambridge University Press, Cambridge : p. 65-108.

CPTEC. Boletim Técnico: Instituto Nacional de Pesquisas Espaciais. 2016. Centro de Previsão de Tempo e Estudos Climáticos. Disponível em: http://tempo.cptec.inpe.br/ boletimtecnico/pt. Acesso em: 03 jun. 2020.

DARSAN, J.; ASMATH, H.; JEHU, A. Flood-risk mapping for storm surge and tsunami at Cocos Bay (Manzanilla), Trinidad. Journal of Coastal Conservation, [s.l.], v. 17, n. 3, p. 679-689, ago. 2013. Springer Science and Business Media LLC. http://dx.doi.org/10.1007/s11852-013-0276-x.

DUTRA, F. R. L. S. MARÉS METEOROLÓGICAS E OS EPISÓDIOS DE EROSÃO COSTEIRA SEVERA NO LITORAL DE SALVADOR/BA. 2008. Dissertação (Mestrado em Geologia). Instituto de Geociências, Universidade Federal da Bahia, Salvador. 2008. 166p.

FIGUEIREDO, S.; CALLIARI, L. J. Sangradouros: distribuição espacial, variação sazonal, padrões morfológicos e implicações no gerenciamento costeiro. Gravel, Porto Alegre, p.47-57, nov. 2005.

GOOS-BRASIL. Programa Nacional de Boias. 2017. Disponível em: < http://www.goosbrasil.org/pnboia/>. Acesso em: 14 out. 2017.

GUIMARÃES, P. V.; FARINA, L.; TOLDO JUNIOR, E. E. Analysis of extreme wave events on the southern coast of Brazil. Natural Hazards And Earth System Science, [s.l.], v. 14, n. 12, p. 3195-3205, dez. 2014. DOI: 10.5194/nhess-14-3195-2014.

GUIMARÃES, P. V.; FARINA, L.; TOLDO Jr.; DIAZHERNANDEZ, G.; AKHMATSKAYA, E. Numerical simulation of extreme wave runup during storm events in Tramandaí Beach, Rio Grande do Sul, Brazil. Coastal Engineering, [s.l.], v. 95, p.171-180, jan. 2015. DOI: 10.1016/j.coastaleng.2014.10.008.

HESP, P. Morphology, dynamics and internal stratification of some established foredunes in southeast Australia. Sedimentary Geology, [s.l.], v. 55, n. 1-2, p.17-41, mar. 1988. DOI: 10.1016/0037-0738(88)90088-7.

HOEKE, R.; MCINNES, K.; O'GRADY, J. Wind and Wave Setup Contributions to Extreme Sea Levels at a Tropical High Island: a stochastic cyclone simulation study for apia, samoa. : A Stochastic Cyclone Simulation Study for Apia, Samoa. Journal of Marine Science and Engineering, [s.l.], v. 3, n. 3, p. 1117 1135, 22 set. 2015. MDPI AG. http://dx.doi.org/10.3390/ jmse3031117.

HÖFFKEN, J.; VAFEIDIS, A. T.; MACPHERSON, L. R.; DANGENDORF, S. Effects of the Temporal Variability of Storm Surges on Coastal Flooding. Frontiers in Marine Science, [s.1.], v. 7, p. 1-14, 21 fev. 2020. Frontiers Media SA. http://dx.doi. org/10.3389/fmars.2020.00098.

HUBBERT, G. D.; MCINNES, K. L. A Storm Surge Inundation Model for Coastal Planning and Impact Studies. Journal of Coastal Research, Royal Palm Beach (florida), v. 15, n. 1, p. 168-185, 09 jan. 1999.

IBGE. Cidades e estados. 2019. Disponível em: <https:// cidades.ibge.gov.br/>. Acesso em: 09 ago. 2019.

INMET. Estações Automáticas. 2017. Disponível em: $<$ http://www.inmet.gov.br/portal/index.php?r=estacoes/ estacoesautomaticas>. Acesso em: 14 out. 2017.

IPCC. Climate Change 2014: Synthesis report. Contribution of working groups I, II and III to the fifth assessment report of the Intergovernmental Panel on Climate Change. Genebra: IPCC, 2014. 151 p. Disponível em: https://archive.ipcc.ch/pdf/ assessment-report/ar5/syr/SYR_AR5_FINAL_full_wcover.pdf. Acesso em: 08 jun. 2020.

$Ł A B U Z$, T. A.. Erosion and its rate on an accumulative Polish dune coast: the effects of the january 2012 storm surge. : the effects of the January 2012 storm surge. Oceanologia, [s.1.], v. 56, n. 2, p. 307-326, 2014. Elsevier BV. http://dx.doi. org/10.5697/oc.56-2.307.

LEWIS, M.; BATES, P.; HORSBURGH, K.; NEAL, J.; SCHUMANN, G. A storm surge inundation model of the northern Bay of Bengal using publicly available data. Quarterly Journal of the Royal Meteorological Society, [s.l.], v. 139, n. 671, p. 358-369, jan. 2013. Wiley. http://dx.doi. org/10.1002/qj.2040.

MACHADO, A. A.; CALlIARI, L. J. Synoptic Systems Generators of Extreme Wind in Southern Brazil: atmospheric conditions and consequences in the coastal zone: Atmospheric Conditions and Consequences in the Coastal Zone. Journal 
of Coastal Research, [s.l.], v. 75, n. 1, p. 1182-1186, mar. 2016. Coastal Education and Research Foundation. http://dx.doi. org/10.2112/si75-237.1.

MACHADO, A. A.; CALLIARI, L. J.; MELO, E.; KLEIN, A. H. F. Historical assessment of extreme coastal sea state conditions in southern Brazil and their relation to erosion episodes. Pan-american Journal of Aquatic Sciences, [s.l.], v. 2, n. 5, p. 277-286, out. 2010.

MAIA, N. Z.; CALLIARI, L. J.; NICOLODI, J. L. Analytical model of sea level elevation during a storm: Support for coastal flood risk assessment associated with cyclone passage. Continental Shelf Research, [s.l.], v. 124, p. 23-34, ago. 2016. DOI: 10.1016/j.csr.2016.04.012.

MARTINS, L. R. Aspectos deposicionais e texturais dos sedimentos praiais e eólicos da Planície Costeira do Rio Grande do Sul. Publicação Especial da Escola de Geologia, Universidade Federal do Rio Grande do Sul, 13: 1-102, 1967.

MCGUIGAN, K.; WEBSTER, T.; COLLINS, K. A Flood Risk Assessment of the LaHave River Watershed, Canada Using GIS Techniques and an Unstructured Grid Combined RiverCoastal Hydrodynamic Model. Journal of Marine Science and Engineering, [s.I.], v. 3, n. 3, p. 1093-1116, 22 set. 2015. MDPI AG. http://dx.doi.org/10.3390/jmse3031093.

MELO FILHO, E. Maré meteorológica na costa brasileira. Tese (Professor Titular), Escola de Engenharia, Universidade Federal do Rio Grande, Rio Grande. 2017. 328p.

MUSSI, C. S. Avaliação da sensibilidade ambiental costeira e de risco à elevação média dos oceanos e incidência de ondas de tempestade: um estudo de caso para ilha de Santa Catarina, SC. Dissertação (Mestrado em Ciência e Tecnologia Ambiental). Centro de Ciências Tecnológicas da Terra e do Mar, Universidade do Vale do Itajaí, Itajaí. 2011. 128p.

NIMER, E. Climatologia do Brasil. Rio de Janeiro: IBGE, 1989. 422p.

OLIVEIRA, M. P. Análise dos parâmetros meteorológicos e oceanográficos de um evento de maré meteorológica ocorrido em Tramandaí. TCC (Graduação em Geografia). Instituto de Geociências, Universidade Federal do Rio Grande do Sul, Porto Alegre. 2008. 59p.

OLIVEIRA, U. R.; SIMÕES, R. S.; CALLIARI, L. J.; GAUTÉRIO, B. C. Erosão de dunas sob ação de um evento extremo de alta energia de ondas na costa central e sul do Rio Grande do Sul, Brasil. Revista Brasileira de Geomorfologia, [s.l.], v. 20, n. 1, p. 137-158, 2 jan. 2019. DOI: 10.20502/rbg. v20i1.1352.
O SUL. Maior ressaca em quase 20 anos provoca ondas de até 5 metros no Litoral Norte gaúcho. 2016. Disponível em: $<$ http://www.osul.com.br/maior-ressaca-em-quase-20-anosprovoca-ondas-de-ate-5-metros-no-litoral-norte-gaucho/>. Acesso em: 14 out. 2017.

PALMARES DO SUL (Município). Lei Municipal $\mathbf{N}^{\circ} \mathbf{1 4 2 2}$, de 05/10/2006: Institui o plano diretor do município de Palmares do Sul. Palmares do Sul, RS, Disponível em: $<$ https://cespro. com.br/print.php?cdMunicipio=7722\&cdDiploma=20061422>. Acesso em: 09 ago. 2019.

PARISE, C. K.; CALLIARI, L. J.; KRUSCHE, N. Extreme storm surges in the south of Brazil: atmospheric conditions and shore erosion. Brazilian Journal of Oceanography, [s.l.], v. 57, n. 3, p. $175-188$, set. 2009 . DOI: 10.1590/s1679-87592009000300002

PEREIRA, P. S.; CALliARI, L. J.; BARLETTA, R. C. Heterogeneity and homogeneity of Southern Brazilian beaches: A morphodynamic and statistical approach. Continental Shelf Research, [s.I.], v. 30, n. 3-4, p. 270-280, fev. 2010. DOI: 10.1016/j.csr.2009.11.007

PUGH, D. Changing Sea Levels: Effects of Tides, Weather and Climate. Cambridge University Press, 2004. 280 p.

RAJI, O.; DEL RÍO, L.; GRACIA, F. J.; BENAVENTE, J. The use of LIDAR data for mapping coastal flooding hazard related to storms in Cádiz Bay (SW Spain). Journal of Coastal Research, [s.l.], n. 64, p. 1881-1885, 2011.

RIO GRANDE DO SUL (Estado). Lei n ${ }^{\circ} 11520$, de 03 de agosto de 2000. Institui o Código Estadual do Meio Ambiente do Estado do Rio Grande do Sul e dá outras providências. Porto Alegre, RS, Disponível em: <http://www.icmbio.gov.br/ cepsul/images/stories/legislacao/Lei/2000/lei_11520_2000_ instituicodigoestadualmeioambiente_rs_regulamentada_ dec_46519_2009.pdf>. Acesso em: 09 ago. 2019.

ROHDE, G. M. A origem geológica das formações de TorresRS. Boletim Geográfico do Rio Grande do Sul, Porto Alegre, n. 18, p. 88-91, 1975.

ROSSATO, M. S. Os climas do Rio Grande do Sul: Variabilidade, tendências e tipologia. Tese (Doutorado em Geografia). Instituto de Geociências, Universidade Federal do Rio Grande do Sul, Porto Alegre. 2011. 240P.

SARAIVA, J. M. B.; BEDRAN, C.; CARNEIRO, C. Monitoring of Storm Surges on Cassino Beach, RS, Brazil. Journal of Coastal Research, [s.l.], n. 35, p. 323-331, spring 2003.

SEELIGER, U. A. (1998). Flora das Dunas Costeiras. In: SEELIGER, U.; ODEBRECHT, C.; CASTELLO, J. P. (org.). Os 
Ecossistemas Costeiro e Marinho do Extremo Sul do Brasil. Ecoscientia, Rio Grande: p. 109-11.

SEELIGER, U.; CORDAZZO, C.; BARCELlOS, L. Areias do Albardão: um guia ecológico ilustrado do litoral no extremo sul do Brasil. Rio Grande: Ecoscientia, 2004. 96p.

SOARES, Liege. [Imagens da ressaca em Torres]. 2016. 2 fotografias.

SOUZA, Alina. Água do mar invadiu os quiosques na beira da praia. 2016. 1 fotografia.

STANEVA, J.; WAHLE, K.; KOCH, W.; BEHRENS, A.; FENOGLIO-MARC, L.; STANEV, E. V. Coastal flooding: impact of waves on storm surge during extremes - a case study for the German Bight. Natural Hazards And Earth System Sciences, [s.1.], v. 16, n. 11, p. 2373-2389, 21 nov. 2016. Copernicus GmbH. http://dx.doi.org/10.5194/nhess-16-2373-2016.

STRAUCH, J.; CUCHIARA, D. C.; TOLDO Jr, E. E.; ALMEIDA, L. E. S. B. O Padrão das Ondas de Verão e Outono no Litoral Sul e Norte do Rio Grande do Sul. Revista Brasileira de Recursos Hídricos, [s.l.], v. 14, n. 4, p. 29-37, 2009. DOI: 10.21168/rbrh.v14n4.p29-37

SUANEZ, S.; CANCOUËT, R.; FLOC'H, F.; BLAISE, E.; ARDHUIN, F.; FILIPOT, J.; CARIOLET, J.; DELACOURT, C. Observations and Predictions of Wave Runup, Extreme Water Levels, and Medium-Term Dune Erosion during Storm Conditions. Journal of Marine Science and Engineering, [s.l.], v. 3, n. 3, p. 674-698, 24 jul. 2015. MDPI AG. http://dx.doi. org/10.3390/jmse3030674.

TOMAZELLI, L. J. O Regime dos Ventos e a Taxa de Migração das Dunas Eólicas Costeiras do Rio Grande do Sul,
Brasil. Pesquisas, Porto Alegre, v. 20, n. 1, p. 18-26, jan. 1993.

TOMAZELLI L. J.; VILLWOCK J. A. (2000). O cenozóico costeiro do rio grande do sul. In: Holz, M; De Ros, L F. (org.). Geologia do Rio Grande do Sul. UFRGS, Porto Alegre: p. 175-406.

VIANNA, H. D.; CALLIARI, L. J. Variabilidade do sistema praia-dunas frontais para o litoral norte do Rio Grande do Sul (Palmares do Sul a Torres, Brasil) com o auxílio do Light Detection and Ranging - LIDAR. Pesquisas em Geociências, Porto Alegre, v. 2, n. 42, p. 141-158, Mai-ago. 2015. DOI: $10.22456 / 1807-9806.78116$

VIANNA, H. D.; CALLIARI, L. J. Variabilidade granulométrica do sistema praia dunas ao longo do litoral norte do Rio Grande do Sul, Brasil. Revista Mundi Engenharia, Tecnologia e Gestão, Curitiba, v. 2, n. 1, p. 1-13, Jan-jun. 2017. DOI: 10.21575/25254782rmetg2017vol2n1332

VIANNA, H. D.; CALLIARI, L. J. Diversidade morfológica das dunas frontais no litoral norte do Rio Grande Do Sul, Brasil. Revista Brasileira de Geomorfologia (Online), São Paulo, v. 20, n. 2, p. 339-359, Abr.-Jun. 2019. DOI: 10.20502/ rbg.v20i2.1473

WEBSTER, T. L.; FORBES, D. L.; DICKIE, S.; SHREENAN, R. Using topographic LIDAR to map flood risk from stormsurge events for Charlottetown, Prince Edward Island, Canada. Canadian Journal of Remote Sensing, [s.l.], v. 30, n. 1, p.64-76, 02 jun. 2004. DOI: 10.5589/m03-053

WRIGHT, L. D; SHORT, A. D. Morphodynamic variability of surf zones and beaches: A synthesis. Marine Geology, [s.l.], v. 56, n. 1-4, p.93-118, abr. 1984. DOI: 10.1016/00253227(84)90008-2. 